\title{
Some aspects of elemental behaviour in HVOF MCrAIY coatings in high-temperature oxidation
}

\author{
Kang Yuan, Ru Lin Peng, Xin-Hai Li, Sten Johansson and Yandong Wang
}

\section{Linköping University Post Print}

\section{Tweet}

N.B.: When citing this work, cite the original article.

Original Publication:

Kang Yuan, Ru Lin Peng, Xin-Hai Li, Sten Johansson and Yandong Wang. Some aspects of elemental behaviour in HVOF MCrAlY coatings in high-temperature oxidation, 2015, Surface \& Coatings Technology, 261, 86-101.

http://dx.doi.org/10.1016/j.surfcoat.2014.11.053

Copyright: Elsevier

http://www.elsevier.com/

Postprint available at: Linköping University Electronic Press

http://urn.kb.se/resolve?urn=urn:nbn:se:liu:diva-111116 


\title{
Some aspects of elemental behaviour in HVOF MCrAlY coatings in high- temperature oxidation
}

\author{
Kang Yuan ${ }^{1, \mathrm{a}}$, Ru Lin Peng ${ }^{1, \mathrm{~b}}$, Xin-Hai Li ${ }^{2, \mathrm{c}}$, Sten Johansson ${ }^{1, \mathrm{~d}}$, Yan-Dong Wang, \\ ${ }^{1}$ Department of Management and Engineering, Linköping University, SE-58183 Linköping, Sweden \\ ${ }^{2}$ Siemens Industrial Turbomachinery AB, SE-61283 Finspång, Sweden \\ ${ }^{3}$ University of Science and Technology, Beijing 100083, China \\ akang.yuan@liu.se, ${ }^{b}$ ru.peng@liu.se, ${ }^{\mathrm{c} x i n}$-hai.li@siemens.com, ${ }^{\mathrm{d}}$ sten.johansson@liu.se, \\ eydwang@mail.neu.edu.cn
}

Keywords: MCrAlY; oxidation; interdiffusion; elemental behaviour.

\begin{abstract}
MCrAlY coatings are widely used to protect superalloys against oxidation and corrosion at high temperature in gas turbine engines. To design a durable MCrAlY coating, the behaviour of alloying elements in coating-superalloy system needs to be better understood. After oxidation tests in temperature range between $900{ }^{\circ} \mathrm{C}$ to $1100{ }^{\circ} \mathrm{C}$, the development of the microstructures in the samples was analysed at the coating surface or in areas near the coatingsuperalloy interface. Some interdiffusion simulations were also done to model the diffusion behaviour of alloying elements in different coating-superalloy couples. The results show that both oxidation at the coatings' surface and the elements' diffusion inside of the materials were temperature- and chemical-composition dependent. The behaviour of some minor elements like $\mathrm{Y}, \mathrm{Hf}, \mathrm{Ru}$ and Ir in the oxidation processes was particularly studied by tracking their position and composition in the materials.
\end{abstract}

\author{
Abbreviations \\ high-velocity oxy-fuel (HVOF) \\ coating-substrate interface (CSI) \\ inner- $\beta$-depletion zone (IBDZ) \\ $\gamma^{\prime}$-depletion zone (GPDZ) \\ secondary $\beta$ phase (SBP)
}

\section{Introduction}

MCrAlY coatings ( $\mathrm{M}$ for $\mathrm{Ni}$ and/or $\mathrm{Co}$ ) are widely used to protect the base materials (superalloys) against high-temperature oxidation and hot corrosion in gas turbine engines. Two important issues always capture researchers' attention when the oxidation behaviour of MCrAlY- 
coated superalloys is investigated at high temperature: the formation of oxides at coating surface, and the interdiffusion-induced microstructural evolution at the coating-substrate interface (CSI).

MCrAlY coatings are good alumina formers [1,2]. At high temperature, a continuous and protective alumina scale can form at MCrAlY surface, to protect the coating and base material against high-rate oxidation. Dependent on coating composition and temperature, other oxides like $\mathrm{Cr}_{2} \mathrm{O}_{3}, \mathrm{CoO}, \mathrm{NiO}$, and spinels may also form [1-3]. Brandl et al.'s results showed that, besides alumina, $\mathrm{Cr}_{2} \mathrm{O}_{3}$ formed at $950{ }^{\circ} \mathrm{C}$ while $\mathrm{NiAl}_{2} \mathrm{O}_{4}$ and $\mathrm{CoAl}_{2} \mathrm{O}_{4}$ spinels formed at higher temperature $\left(1050{ }^{\circ} \mathrm{C}\right)$ on a NiCoCrAlYRe coating. The oxidation behaviour of MCrAlY coatings was also influenced by the surface modification [4,5] and coating spraying technique $[3,6,7]$. For instance, ground and polished samples performed an accelerated oxidation due to surface deformation [5]. Coatings sprayed by high-velocity oxy-fule (HVOF) technique may have a slower oxidation rate than coatings sprayed by VPS, due to a probable diffusion-blocking effect by some small alumina formed in the coatings after HVOF spraying [3].

The microstructural evolution near the coating-substrate interface (CSI) was dependent on coating composition, substrate composition, and temperature [8,9]. For instance, due to the diffusion of Co into the substrate, secondary $\beta$ phase (SBP) may form in the substrate [8]. Taylor et al.'s result [10] further showed that the Al in the SBP could diffuse back to the coating and be used for the oxidation at the coating surface. TCP phases, like $\sigma-\mathrm{CrW}$, may also form near the CSI due to the interdiffusion of alloying elements in some coating-superalloy systems [11]. In coating side, due to the diffusion of $\mathrm{Al}$ into the substrate, there usually formed a $\beta$-depletion zone [8]. With development of thermodynamic and kinetic databases in recent decades, the microstructural evolution in coating-superalloy systems can be simulated $[9,12,13]$.

The current work focuses on the behaviour of main elements $(\mathrm{Ni}, \mathrm{Co}, \mathrm{Cr}$ and $\mathrm{Al})$ and some minor elements (Y, Hf, Ru and Ir) in some HVOF MCrAlY coatings during high-temperature oxidation processes at 900 to $1100{ }^{\circ} \mathrm{C}$. The diffusion behaviour of alloying elements was also simulated by using DICTRA software [14]. This paper is aiming at providing knowledge for designing new MCrAlY coatings to be used for the oxidation protection at high temperatures.

\section{Experimental and simulation}

The MCrAlY coatings were sprayed by using high-velocity oxy-fuel (HVOF) technique. The thickness of the coatings was in a range about 170 to $200 \mu \mathrm{m}$. The substrate material to hold the coatings was a Ni based superalloy - Inconel 792. The nominal compositions of the MCrAlY coatings and the substrate are shown in Table I. A0, A1 and A2 were Ni based MCrAlY coatings, and B0, B1, B2 and B3 were Co based ones. The heat treatment on the samples after the HVOF

spray included a solution annealing at $1120{ }^{\circ} \mathrm{C}$ for 2 hours in vacuum and an ageing treatment at $845^{\circ} \mathrm{C}$ for 24 hours in air. Such heat treatment was similar to the practice in industry, aiming at 
improving the bonding strength of the CSI and strengthening the substrate by creating $\gamma$ ' precipitates. After the heat treatment, the porosity in the coatings was lower than $1 \%$.

The samples were subjected to oxidation at $900{ }^{\circ} \mathrm{C}, 1000{ }^{\circ} \mathrm{C}$, or $1100{ }^{\circ} \mathrm{C}$ in air. The microstructural development in the materials was studied after different exposure times. The samples were cross-sectioned and polished for the investigations in an optical microscope (OP) and a scanning electron microscope (SEM). In the SEM, there are two modes to image the microstructures in the materials: secondary-electron (SE) mode, and backscattered-electron (BSE) mode. SE images capture surface-sensitive morphologies while BSE images usually give atomic and crystalline contrasts. Chemical compositions were measured by using energy dispersive spectroscope (EDS) and wavelength dispersive spectroscope (WDS) in the SEM.

To better understand the behaviour of the alloying elements in the materials at such high temperatures, some thermodynamic calculations and diffusion simulations were carried out. For instance, some ternary phase diagrams were calculated by using ThermoCalc, and interdiffusion simulations was performed in a "rule of mixture" homogenization model by DICTRA $[9,13,14]$. In the interdiffusion simulations in the coating-substrate diffusion couples $(150 \mu \mathrm{m}$ coating and $200 \mu \mathrm{m}$ substrate), the diffusion behaviour of the alloying elements through the CSI was simulated. Since the simulations were only for diffusion processes when there still reserved a lot of $\beta$-NiAl phase in the coating (the $\beta$ phase can provide $\mathrm{Al}$ for the surface oxidation), the surface oxidation was believed to have no significant influence on the microstructural development near the CSI. Therefore, the surface oxidation was not considered in the simulations. The input compositions of the coatings and the substrate in the simulations used the nominal compositions as given in Table I; to avoid a sudden change of the elemental concentrations at the CSI, the input composition profiles for the simulations were gently smoothed at the CSI by using error equations.

\section{Results}

\subsection{Coatings as-received and heat-treated}

Fig. 1a shows the morphology of the powders used for the HVOF spray. The average diameter is about $30 \mu \mathrm{m}$. The cross section of the powder particles in Fig. 2b (BSE image) shows some dendrite-like morphology; the dark-grey phases are $\mathrm{Ni}, \mathrm{Al}$ rich, while the light-grey phases are $\mathrm{Co}, \mathrm{Cr}$ rich.

The cross section of an as-received coating is shown in Fig. 2a. Splat-on-splat structures can be seen with some cracks and pores which mark the splats' interfaces. Among the splats, $\mathrm{O}$ and $\mathrm{Si}$ are rich along the splats' interfaces, while $\mathrm{Y}$ is uniformly distributed (Fig. 2b).

After the solution and ageing heat treatment, a typical $\gamma+\beta$ microstructure forms in coatings, as shown in Fig. 3a (in coating part, dark phases are mainly pores, dark-grey phases are $\beta$, and light- 
grey phases are $\gamma$ ). Comparing with the as-received coating (Fig. 2a), the amount of cracks and pores is significantly reduced due to a sintering effect during the heat treatment; the porosity of the coatings becomes less than $1 \%$. The quality and the bonding strength of the CSI are also improved. In addition, the distribution of the alloying elements in the coating is also changed (Fig. 3b) from the as-received status (Fig. 2b). For instance, Si is dissolved into the metallic phases in the splats, while Y tends to move to the splats' interfaces.

\subsection{Interdiffusion during oxidation}

The oxidation tests at high temperatures $\left(900{ }^{\circ} \mathrm{C}, 1000^{\circ} \mathrm{C}\right.$, and $\left.1100{ }^{\circ} \mathrm{C}\right)$ cause the microstructural development near the CSI. The study on the microstructures in the samples shows that $\mathrm{A} 1$ and $\mathrm{A} 2$ have the same microstructural development as $\mathrm{A} 0$, while $\mathrm{B} 1, \mathrm{~B} 2, \mathrm{~B} 3$ share the same behaviour as B0, therefore, the microstructural evolution due to the interdiffusion of alloying elements can be focused in $\mathrm{A} 0$ and $\mathrm{B} 0$.

At $900{ }^{\circ} \mathrm{C}$ for 5000 hours (Fig. 4), A0 and B0 show considerably different microstructures at the CSI. In A0, due to the diffusion of Al into the substrate, $\beta$ phase in the coating is depleted in a certain thickness and $\gamma^{\prime}$ phase formed in this $\beta$-depletion zone. Such $\beta$-depletion zone is termed inner- $\beta$-depletion zone (IBDZ). In B0, there is no IBDZ formed in the coating for 5000 hours. Furthermore, $\beta$ phase forms in the substrate in a $\gamma^{\prime}$-depletion zone (GPDZ); such $\beta$ phase is termed secondary $\beta$ phase (SBP). Some Ta-Ti-carbides are also found in the GPDZ, which may form due to the dissolution of the original large Ta-Ti-carbides in the substrate followed by the re-precipitation of the carbides in the GPDZs.

At $1000{ }^{\circ} \mathrm{C}$, an IBDZ forms with a $\beta \rightarrow \gamma$ transition in A0 for 1500 hours (Fig. 5a), but after a longer time (5000 hours) $\beta \rightarrow \gamma^{\prime}$ transition occurs in the IBDZ (Fig. 5b). In B0 at $1000{ }^{\circ} \mathrm{C}$, the microstructure after 1500 hours (Fig. 5c) is similar to that at $900{ }^{\circ} \mathrm{C}$ for 5000 hours (Fig. 4b), i.e. SBP forming in the substrate and no IBDZ forming in the coating. With a longer time at $1000{ }^{\circ} \mathrm{C}$ (5000 hours), the SBP disappears and an IBDZ forms in the coating (Fig. 5d).

With another $100{ }^{\circ} \mathrm{C}$ increase of the oxidation temperature (at $1100{ }^{\circ} \mathrm{C}$, Fig. 6), IBDZ forms in both coatings (A0 and $\mathrm{B} 0$ ) with similar thicknesses but with ten-time shorter times. In other words, the $\beta$-depletion rate in the coatings, due to the interdiffusion, appears to be about ten-time faster with a $100{ }^{\circ} \mathrm{C}$ increase of the oxidation temperature, which agrees with the results by diffusion modelling [9]. The $\gamma^{\prime}$-depletion rate in the substrate is also highly accelerated at the higher temperature.

The coating-substrate systems, at the high temperatures, behave as diffusion couples. The diffusion direction of the alloying elements is determined by their thermal activities. As an example, Fig. 7 shows the activity profiles of the alloying elements in the A0-substrate couple at $900{ }^{\circ} \mathrm{C}$ for 5000 hours by the interdiffusion simulation; such activity results are corresponded to the composition-profile results in Fig. 8b. The results in Fig. 7 indicate a diffusion process with $\mathrm{Co}$ and $\mathrm{Al}$ moving from the coating to the substrate and the other elements in the opposite 
direction, since only the activities of $\mathrm{Co}$ and $\mathrm{Al}$ are higher in the coating than that in the substrate. The difference of the microstructural evolution near the CSI between A0-substrate and B0substrate couples is definitely due to the difference of the coating compositions. Since A0 and B0 have a similar $\mathrm{Al}$ content, the difference should be related to the $\mathrm{Co}$ and $\mathrm{Cr}$ contents in the two coatings.

Fig. 8 and 9 give the simulation results (curves) of microstructure and composition in the A0substrate and B0-substrate couples, with a comparison with some experimental data (dots). The calculated profiles have somewhat fluctuations due to the numerical instability of the DICTRA simulations, for instance on the phase profiles in Fig 8. Ignoring the numerical fluctuations, the simulated microstructures in the A0-substrate couple are basically comparable with the experimental observations. The composition profiles, especially the profiles of the four main elements ( $\mathrm{Ni}, \mathrm{Co}, \mathrm{Cr}$ and $\mathrm{Al}$ ), are also well predicted by the simulation. According to those results, how the $\beta$ phase is depleted in the coating seems to be mainly related to the diffusion of Co from the coating to the substrate. For instance, at $1000{ }^{\circ} \mathrm{C}$ and $1100{ }^{\circ} \mathrm{C}$, there forms Co-rich zones near the CSI (the Co concentration is about $7 \%$ higher than that in the mid of the coating) where $\mathrm{Cr}$ is also rich (the $\mathrm{Cr}$ concentration is about $6 \%$ higher than that in the mid of the coating) but the $\mathrm{Ni}$ and $\mathrm{Al}$ contents are low (the $\mathrm{Ni}$ and $\mathrm{Al}$ concentrations are about $8 \%$ and 5\%, respectively, lower than that in the mid of the coating), which promotes the formation of $\beta$ depleted zones, i.e. IBDZ, in the coating, and the formation of GPDZ in the substrate; $\gamma^{\prime}$ becomes unstable when the concentrations of $\mathrm{Co}$ and $\mathrm{Cr}$ are high (e.g. when $\mathrm{Co}$ is above $25 \%$ or $\mathrm{Cr}$ is above $20 \%$ at $1000{ }^{\circ} \mathrm{C}$ in $\mathrm{NiCoCr}-5 \mathrm{Al}-1.5 \mathrm{Mo}-0.5 \mathrm{Si}-3 \mathrm{Ta}-3 \mathrm{Ti}-3 \mathrm{~W}$ alloys [9]). At $900{ }^{\circ} \mathrm{C}$, however, $\mathrm{Co}$ and $\mathrm{Cr}$ concentrations in areas near the CSI (about $20 \mathrm{wt} \% \mathrm{Co}, 15 \mathrm{wt} . \% \mathrm{Cr}$ ) are not as high as that at $1000{ }^{\circ} \mathrm{C}$ (about 28 wt. $\%$ Co, 22 wt.\% Cr) and $1100{ }^{\circ} \mathrm{C}$ (about 25 wt.\% Co, 18 wt. $\% \mathrm{Cr}$ ), so $\gamma^{\prime}$ phase can form when the coating lose $\mathrm{Al}$ into the substrate and $\beta$ phase is depleted.

For the B0-substrate couple (Fig. 9), the composition profiles predicted are barely satisfactory due to the limitation of the database used. Therefore, the microstructures predicted were imperfect either. By focusing on the experimental data, i.e. the dots in the graphs, one can see that from $900{ }^{\circ} \mathrm{C}$ to $1100{ }^{\circ} \mathrm{C}$, Co and $\mathrm{Cr}$ peaks form at the CSI where a Ni valley is found. In other words, Co and $\mathrm{Cr}$ replace $\mathrm{Ni}$ near the CSI, which causes the microstructure changes [8]. SBP forms in the substrate in short time, but gradually disappears with longer time (see Fig. 5c, d or Fig. 6c, d), probably due to a further diffusion of Al in the SBP into the deeper substrate or due to a back diffusion of Al from the SBP to the coating [10].

Fig. 10 presents the results of the compositions of Y, Ru and Ir in coating-substrate couples by EDS measurement. In those graphs, the color bars attaching the CSI stand for the thickness of the GPDZs forming in the substrate. The size of the GPDZs can be taken as a characteristic scale marking the diffusion depths of alloying elements like Co and $\mathrm{Al}$ from the coating into the substrate. Since the uncertainty range of the EDS measurement is about $0.2 \mathrm{wt} \%$ mainly due to an overlap of the EDS peaks from different elements, $0.2 \mathrm{wt} . \%$ is taken as the detectable level for those minor elements. As shown in Fig. 10a, Y is only detected in the coating part even after 
long-term thermal exposure. That could be due to that $\mathrm{Y}$ is mainly in oxide form in the HVOF coatings, making $\mathrm{Y}$ hardly diffuse into the substrate. Ru and Ir have a different behaviour from Y (Fig. 10b and c); they diffuse from the coating to the substrate with the same diffusion depths as the thickness of the GPDZs. Some literatures [15,16] claimed that $\mathrm{Ru}$ and Ir could hardly dissolve in the $\gamma^{\prime}$ phase in superalloys, which is probably the reason that $\mathrm{Ru}$ and Ir is only detected in the coating or in the GPDZs. Furthermore, our previous results [17] showed that Ru and Ir mainly dissolved in the $\beta$ phase in MCrAlY (Fig. 11). In addition, Ru and Ir are not detected as oxides at the coating surface, nor to dissolve in alumina scales in this study.

The ability of an element to stabilize a phase can be investigated by studying the effect of the element on the extension of the phase field in phase diagram. For instance, Ochiai et al. [18] analysed the stability of $\gamma^{\prime}$ phase in a Ni-Al-X phase diagram. By applying such approach, Ni-Al$\mathrm{X}$ ternary phase diagrams are draw in Fig. 12, by highlighting the extension of $\gamma^{\prime}$ and $\beta$ fields due to the addition of the third element $\mathrm{X}$ in $\mathrm{Ni}_{3} \mathrm{Al}$ or $\mathrm{NiAl}$ alloys. The extended phase field of $\gamma^{\prime}$ (Fig. $12 \mathrm{a}$ ) and $\beta$ (Fig. 12b) is a collection of many Ni-Al-X phase diagrams in literature and by calculation using ThermoCalc software; the details are shown in Table II. The site preference of the $\mathrm{X}$ elements in the $\mathrm{FCC} \mathrm{Ni} 3 \mathrm{Al}$ cell or in the $\mathrm{BCC} \mathrm{NiAl}$ cell is also presented in Fig. 12 with red for strong Al-site preference, blue for strong Ni-site preference, and green for slight site preference or no preference. Note that the site preference is only for the case that a small fraction of an $\mathrm{X}$ element is added into $\mathrm{Ni}_{0.75} \mathrm{Al}_{0.25}$ or $\mathrm{Ni}_{0.5} \mathrm{Al}_{0.5}$ chemistries by either simulations or experiments. The diagrams in Fig.12 can provide a basic knowledge of how the alloying elements affect the stability of $\gamma^{\prime}$ and $\beta$ phases at high temperatures, even for multi-component MCrAlY coatings and superalloys. For instance, Fig. 12a shows that Ru and Ir can hardly dissolve in the $\gamma^{\prime}$ phase (limited size of the $\gamma^{\prime}$-phase field) while the result in Fig. 12b indicates that Ru and Ir can greatly stabilize the $\beta$ phase by largely extending the $\beta$ phase field in the phase diagram.

\subsection{Oxidation}

The MCrAlY coatings in this study are good alumina formers at high temperature in oxidation. Continuous and dense alumina scales can form at the coating surfaces. Besides the alumina, the $\mathrm{XRD}$ results (Fig. 13) show that other oxides, typically $(\mathrm{Co}, \mathrm{Ni})(\mathrm{Cr}, \mathrm{Al})_{2} \mathrm{O}_{4}$ spinels, also form. The crystalline structure of the spinels is found to be strongly related to the oxidation temperature. As shown in Fig. 13, the spinels have a $\mathrm{CoCr}_{2} \mathrm{O}_{4}$ structure at lower temperature $\left(900{ }^{\circ} \mathrm{C}\right)$, but own a $\mathrm{CoAl}_{2} \mathrm{O}_{4}$ structure at higher temperature $\left(1100{ }^{\circ} \mathrm{C}\right)$, and with both types at the medium temperature $\left(1000{ }^{\circ} \mathrm{C}\right)$. This result is further confirmed by measuring the chemical composition of the spinels (Fig. 14). In both A0 and B0, the spinels at $900{ }^{\circ} \mathrm{C}$ have a very low Al content $(\sim 0$ to 5 at. $\%$ ) and a high $\mathrm{Cr}$ content ( 25 to 30 at.\%), coinciding to the $\mathrm{CoCr}_{2} \mathrm{O}_{4}$ form. However at $1100{ }^{\circ} \mathrm{C}$, the spinels contain a higher $\mathrm{Al}$ content $(\sim 20$ at. $\%)$ and a lower $\mathrm{Cr}$ content $(\sim 10$ at. $\%)$ to coincide with the $\mathrm{CoAl}_{2} \mathrm{O}_{4}$ form.

Fig. 15a shows a cross section of a coating in which Al-rich $\beta$ phase is highly depleted due to both the surface oxidation and the diffusion of $\mathrm{Al}$ into the substrate after an isothermal oxidation 
at $1100{ }^{\circ} \mathrm{C}$. The EDS mapping results in Fig. $15 \mathrm{~b}$ show that $\mathrm{Y}$, as oxides, is preferably distributed along the splats' interfaces and on the coating surface. In addition, in a cyclic oxidation process as shown in Fig. 16, alumina scale can partially spall off and then a new alumina scale forms, which causes the layer-by-layer morphology of alumina at the coating surface; the thermal cycling is a temperature cyclic process with one-hour heating at $1100{ }^{\circ} \mathrm{C}$ and ten-minute cooling down to $100{ }^{\circ} \mathrm{C}$ by forced air. Since Y can be found on each alumina scale surface, it is believed that during the oxidation process $\mathrm{Y}$ can diffuse to the surface to participate in the oxidation.

Besides Y, another oxygen-affinitive element, Hf, also plays a critical role in the growth of alumina scales. As shown in Fig. 17, Hf is mainly segregated at the grain boundaries of alumina. Some Hf and Y rich particles can be found inside the coating, which can be probably Y-Hf-rich oxides (Fig. 18). Fig. 19 shows a comparison of the oxidation behaviour of the coatings without (B0) and with Hf (B3). A much higher oxidation rate occurs in B3 with a typically uneven inward growth of alumina scale (Fig. 19e and f), indicating that the segregation of $\mathrm{Hf}$ at the grain boundaries of the alumina accelerated the inward diffusion of oxygen and the inward growth of alumina scale.

\section{Discussion}

For the MCrAlY coatings, the main elements are $\mathrm{Ni}, \mathrm{Co}, \mathrm{Cr}$ and $\mathrm{Al}$ which usually have high concentrations, while other elements like $\mathrm{Y}$ and Hf are added with small amounts, being called minor elements. Based on the results obtained above, the following discussion will focus on the role of those elements in the phase stability in MCrAlY coatings, microstructural evolution at CSI, and oxidation performance at the coating surfaces.

\subsection{Main elements (Ni, Co, Cr, and Al)}

\subsection{1. $\beta$ phase stability}

The microstructure of free-standing MCrAlY coatings is mainly dependent on their composition and the operation temperature, usually having a phase combination of $\gamma+\beta$ or $\gamma+\beta+$ others $[1,62] . \beta$ is a BCC phase and has a NiAl-based chemistry in which other elements like $\mathrm{Co}$ and $\mathrm{Cr}$ can be dissolved. The results in Fig. 12 have shown that Co prefers to stay in the $\mathrm{Ni}$ sites in $\beta$ phase; Co can even totally replace $\mathrm{Ni}$ in the $\beta$ phase as shown in the Ni-Al-X diagram. $\mathrm{Cr}$ shows no special preference on $\mathrm{Ni}$ and $\mathrm{Al}$ sites in the $\beta$ phase, but usually occupies the sites on which the element $(\mathrm{Ni}$ or $\mathrm{Al})$ is poorer in content [23,28]. The composition limit for $\mathrm{Cr}$ induced extension of the $\beta$ phase field is around 15 at.\% in the Ni-Al-X diagram. Because of this, in a $\gamma+\beta$ coating $C r$ usually has a higher solubility in $\gamma$ phase than in $\beta$ phase.

\subsection{2. $\gamma^{\prime}$ phase stability}


Up to around 25 at.\%, Co can be dissolved in $\gamma^{\prime}-\mathrm{Ni}_{3} \mathrm{Al}$ phase by occupying the Ni sites (Fig. 12); keep in mind that the total $\mathrm{Ni}$ sites are 75 at.\% in the FCC cell. $\mathrm{Cr}$ has around 10 at.\% solubility in the $\mathrm{Ni}_{3} \mathrm{Al}$ to replace $\mathrm{Ni}$ and around 5 at.\% to replace $\mathrm{Al}$. In multicomponent superalloys where many other alloying elements are also added, Co and $\mathrm{Cr}$ usually lose their competitiveness to occupy the $\mathrm{Ni}$ or $\mathrm{Al}$ sites in the $\gamma$ ' phase, and mostly dissolve in the disordered $\gamma$ phase. Due to that, increasing the content of $\mathrm{Co}$ and/or Cr usually makes $\gamma^{\prime}$ unstable at high temperatures. This result is quite important for understanding the microstructure changes in $\gamma+\gamma$ ' substrate due to the interdiffusion effect at the CSI, for instance the depletion of $\gamma^{\prime}$ in the substrate due to the enrichment of $\mathrm{Co}$ and $\mathrm{Cr}$.

\subsubsection{Microstructural evolution near CSI}

Due to their higher activity on the coating side (Fig. 7), Al and Co diffuse into the substrate, while other elements diffuse towards from the substrate into the coating. The interdiffusion of the alloying elements drives the microstructure changes [9]. Itoh et al.'s research [8] indicated that the microstructures in the substrate were mainly controlled by the diffusion of Co (and Ni) through the CSI, which agrees with the results in this work. The microstructures in the GPDZ are different when the substrate is coated with different coatings (Fig. 4 to 6), which is mainly due to a competition of the diffusion of $\mathrm{Al}$ and $\mathrm{Co}$. The inward diffusion of $\mathrm{Al}$ can cause enrichment of $\mathrm{Al}$ under the GPDZ (see the Al profiles in Fig. 8 and 9). Since Al is usually diffuses faster than $\mathrm{Co}$, the diffusion depth of $\mathrm{Al}$ is larger than that of $\mathrm{Co}$; for instance, the diffusivity of $\mathrm{Al}$ in the $\gamma$ phase is around $1 \mathrm{E}-14 \mathrm{~m}^{2} / \mathrm{s}$ while Co's is around $6 \mathrm{E}-16 \mathrm{~m}^{2} / \mathrm{s}$ at the CSI at $1000{ }^{\circ} \mathrm{C}$ after the interdiffusion for 1500 hours (the values are calculated by DICTRA). However, within a short time, as shown by the microstructures in Fig. 4b, 5c and 6c, some Al may be trapped in the GPDZ to form SBP, which occurs only when a large amount of Co diffuses into the substrate (e.g. being coated with the high Co coating - B0) [9]. The GPDZ may not form in the substrate if being coated with a low Co and Cr coating and the temperature is low (Fig. 4a); in this case, Co does not highly diffuse into the substrate (Fig. 8a).

The contents of $\mathrm{Co}$ and $\mathrm{Cr}$ in the coatings also affect the behaviour of the depletion of $\beta$ phase in the coatings. The results show that a higher $\mathrm{Co}$ and $\mathrm{Cr}$ content, or a higher oxidation temperature, promotes the formation of a pure- $\gamma$ IBDZ in the coating; vice versa the formation of a $\gamma+\gamma^{\prime}$ IBDZ (Fig. 4, 5 and 6).

\subsubsection{Surface oxides}

As shown in Fig. 15, a continuous alumina scale can form at the MCrAlY coating surface in the oxidation processes at high temperature in air. The growth of the scale requires the support of $\mathrm{Al}$ from the coating. If the scale spalls off, especially in a thermal cyclic oxidation condition (Fig. 16), new alumina can form provided that a sufficient amount of $\mathrm{Al}$ exists in the coating.

Besides alumina, $\mathrm{CoCr}_{2} \mathrm{O}_{4}$ or $\mathrm{CoAl}_{2} \mathrm{O}_{4}$ spinels also form, typically above the alumina scale. The results in Fig. 13 and 14 show that the spinels tend to have an Al-dominant $\mathrm{CoAl}_{2} \mathrm{O}_{4}$ 
structure at higher temperature (e.g. $1100{ }^{\circ} \mathrm{C}$ ) but a $\mathrm{Cr}$-dominant $\mathrm{CoCr}_{2} \mathrm{O}_{4}$ structure at lower temperature (e.g. $900{ }^{\circ} \mathrm{C}$ ). Therefore, the structure of the spinels is temperature dependent. The transition from $\mathrm{CoCr}_{2} \mathrm{O}_{4}$ to $\mathrm{CoAl}_{2} \mathrm{O}_{4}$ when increasing temperature can be due to an evaporation of $\mathrm{Cr}$ at the higher temperatures $[63,64]$.

\subsection{Minor elements (Y, Hf, Ru and Ir)}

\subsubsection{Phase stability and diffusion behaviour}

As shown in Fig. 12a, the solubility of $\mathrm{Y}, \mathrm{Ru}$ and $\mathrm{Ir}$ in $\gamma^{\prime}$ is very limited, while $\mathrm{Hf}$ has a similar solubility as $\mathrm{Nb}$ in $\gamma^{\prime}$. The results in Fig. $10 \mathrm{~b}$ and $\mathrm{c}$ show that $\mathrm{Ru}$ and Ir can hardly diffuse into the area where $\gamma^{\prime}$ phase exists. In the $\beta$ phase, $\mathrm{Ru}$ and Ir can expand the phase field largely (Fig. 12b), indicating that $\mathrm{Ru}$ and $\mathrm{Ir}$ are strong $\beta$ phase stabilizers. Hf has a similar solubility as Ti in $\beta$ phase according to the result in Fig. 12b. However, in the HVOF MCrAlY coatings, elements like $\mathrm{Y}$ and Hf which are oxygen-affinitive tend to form oxides at splats' interfaces or at coating surfaces (Fig. 3b, 15b, 17 and 18).

\subsubsection{Surface oxidation}

$\mathrm{Y}$ is added in MCrAlY coatings mainly for improving the adhesion of alumina scales $[65,66]$. $\mathrm{Y}$ can also affect the growth rate of alumina scales. According to some published work, if large Y-oxides form in the alumina scale, the growth rate of the alumina scale will increase due to an increase of the inward diffusion of oxygen along grain boundaries [67-69]. However, if no large Y-oxides form, doping some yttrium in the alumina scale can decrease the grain-boundary diffusion of cations, resulting in a slower oxidation rate [70,71].

The results in Fig. 19 clearly show that the segregation of Hf at the alumina grain boundaries accelerates the inward diffusion of oxygen and causes a higher oxidation rate of the coating, agreeing with some other researches [72,73]. Matsudaira et al's results [71] showed that doping some Hf in an alumina layer could increase the inward diffusion of oxygen along grain boundaries. Therefore, the Hf segregation in alumina scales provides fast diffusion paths for oxygen.

Since no $\mathrm{Ru}$ and $\mathrm{Ir}$ oxides have been found, and those two elements can not be detected in alumina scales or spinels either, it is believed that $\mathrm{Ru}$ and $\mathrm{Ir}$ have no direct influence on the oxidation of the coating. However, some researches claimed that $\mathrm{Ru}$ and $\mathrm{Ir}$ can form oxides in

some RuAl or IrAl alloys, but they were evaporated away at high temperature [74,75]. More study is needed to investigate the influence of $\mathrm{Ru}$ and $\mathrm{Ir}$ on the oxidation behaviour of MCrAlY coatings in the future.

\section{Conclusions}


This paper studies the performance of some HVOF MCrAlY coatings in high-temperature oxidation, with focusing on the behaviour of alloying elements including the main elements $(\mathrm{Ni}$, $\mathrm{Co}, \mathrm{Cr}$ and $\mathrm{Al}$ ) and some minor elements (Y, Hf, $\mathrm{Ru}$ and $\mathrm{Ir}$ ). The main remarks can be summarized as follows.

1. The diffusion of $\mathrm{Al}$ from the coating to the substrate and the enrichment of $\mathrm{Co}$ and $\mathrm{Cr}$ at the coating-substrate interface are the key factors causing the microstructure changes near the coating-substrate interface. The main microstructure changes are, like, the formation of $\beta$ depletion zone in the coating, the formation of secondary $\beta$ phase and $\gamma^{\prime}$-depletion zone in the substrate.

2. Spinels formed at the coating surface, above the alumina scales, are temperature dependent. At a lower temperature (e.g. $900{ }^{\circ} \mathrm{C}$ ), the spinels have a $\mathrm{CoCr}_{2} \mathrm{O}_{4}$ structure, but become a $\mathrm{CoAl}_{2} \mathrm{O}_{4}$ structure at a higher temperature (e.g. $\left.1100{ }^{\circ} \mathrm{C}\right)$.

3. The addition of Hf ( $0.3 \mathrm{wt} . \%)$ causes a significantly accelerated inward growth of alumina scales, by segregating at the grain boundaries of alumina to provide fast diffusion paths for oxygen.

4. $\mathrm{Ru}$ and Ir mainly dissolve in the $\beta$ phase in the MCrAlY coatings, and can hardly diffuse into a $\gamma+\gamma$ ' area in substrate. In addition, $\mathrm{Ru}$ and Ir may be inert in the oxidation at the coating surface.

\section{Acknowledgement}

The Siemens Industrial Turbomachinery AB (Finspång, Sweden) and Swedish Energy Agency through KME consortium - ELFORSK are greatly acknowledged for their financial support, $60 \%$ and $40 \%$ respectively, in this research. The research school of Agora Materials and Strategic Faculty Grant AFM in Linköping University are also acknowledged for their support on this research.

\section{References}

[1] W. Brandl, H.J. Grabke, D. Toma, J. Krüger, The oxidation behaviour of sprayed MCrAlY coatings, Surf. Coat. Technol. 86-87 (1996) 41-47.

[2] W. Beele, N. Czech, W.J. Quadakkers, W. Stamm, Long-term oxidation tests on a re-containing MCrAlY coating, Surf. Coat. Technol. 94-95 (1997) 41-45.

[3] W. Brandl, D. Toma, J. Krüger, H.J. Grabke, G. Matthäus, The oxidation behaviour of HVOF thermalsprayed MCrAlY coatings, Surf. Coat. Technol. 94-95 (1997) 21-26. 
[4] A. Gil, V. Shemet, R. Vassen, M. Subanovic, J. Toscano, D. Naumenko, L. Singheiser, W.J. Quadakkers, Effect of surface condition on the oxidation behaviour of MCrAlY coatings, Surf. Coat. Technol. 201 (2006) 3824-3828.

[5] W. Brandl, G. Marginean, D. Maghet, D. Utu, Effects of specimen treatment and surface preparation on the isothermal oxidation behaviour of the HVOF-sprayed MCrAlY coatings, Surf. Coat. Technol. 188189 (2004) 20-26.

[6] W. Brandl, D. Toma, H.J. Grabke, The characteristics of alumina scales formed on HVOF-sprayed MCrAlY coatings, Surf. Coat. Technol. 108-109 (1998) 10-15.

[7] E. Lugscheider, C. Herbst, L. Zhao, Parameter studies on high-velocity oxy-fuel spraying of MCrAlY coatings, Surf. Coat. Technol. 108-109 (1998) 16-23.

[8] Y. Itoh and M. Tamura, Reaction diffusion behaviors for interface between Ni-based super alloys and vacuum plasma sprayed MCrAlY coatings, Journal of engineering for gas turbines and power 121 (1999) 476-483.

[9] K. Yuan, R. Eriksson, R. Lin Peng, X. Li, S. Johansson, Y. Wang, MCrAlY coating design based on oxidation-diffusion modelling. Part I: Microstructural evolution, Surf. Coat. Technol. 254 (2014) 79-96.

[10] M.P. Taylor, W.M. Pragnell, H.E. Evans, Evidence for the formation of Al-rich reservoir phases resulting from interdiffusion between MCrAlY coating and Ni-based substrate, Mater. Sci. Forum 461464 (2004) 239.

[11] S.M. Jiang, C.Z. Xu, H.Q. Li, J. Ma, J. Gong, C. Sun, High temperature corrosion behaviour of a gradient NiCoCrAlYSi coating I: Microstructure evolution, Corros. Sci. 52 (2010) 1746-1752.

[12] C.E. Campbell, W.J. Boettinger, U.R. Kattner, Development of a diffusion mobility database for Nibase superalloys, Acta mater. 50 (2002) 775-792.

[13] K. Yuan, R. Eriksson, R. Lin Peng, X. Li, S. Johansson, Y. Wang, Modeling of microstructural evolution and lifetime prediction of MCrAlY coatings on nickel based superalloys during high temperature oxidation, Surf. Coat. Technol. 232 (2013) 204-215.

[14] B. Sundman, B. Jansson, J. Andersson, The Thermo-Calc Databank System, Calphad 9 (1985) 153190.

[15] Y. Zhou, Z. Mao, C. Booth-Morrison, D.N. Seidman, The partitioning and site preference of rhenium or ruthenium in model nickel-based superalloys: An atom-probe tomographic and first-principles study, Appl. Phys. Lett. 93 (2008) 171905.

[16] Y. Yamabe-Mitarai, T. Aoyagi, K. Nishida, H. Aoki, T. Abe, H. Murakami, Phase equilibria between the B2, L12, and fcc phases in the Ir-Ni-Al system, Intermetallics 15 (2007) 479-488.

[17] K. Yuan, R. Lin Peng, X. Li, S. Johansson, Y. Wang, Influence of Ru, Mo and Ir on the Behavior of Ni-Based MCrAlY Coatings in High Temperature Oxidation, ASME Turbo Expo 2014: Turbine Technical Conference and Exposition (2014). 
[18] S. Ochiai, Y. Oya, T. Suzuki, Alloying Behavior of Ni sub 3 Al, Ni sub 3 Ga, Ni sub 3 Si and Ni sub 3 Ge, Acta Metall. 32 (1984) 289-298.

[19] Q. Wu and S. Li, Alloying element additions to Ni3Al: Site preferences and effects on elastic properties from first-principles calculations, Comput. Mater. Sci. 53 (2012) 436-443.

[20] C. Jiang and B. Gleeson, Site preference of transition metal elements in Ni3Al, Scr. Mater. 55 (2006) 433-436.

[21] D. Shindo, M. Kikuchi, M. Hirabayashi, S. Hanada, O. Izumi, Site determination of Fe, Co and Cr atoms added in Ni3Al by electron channelling enhanced microanalysis, Trans. Japan Inst. Met. 29 (1988) 956-961.

[22] M.K. Miller and J.A. Horton, Site occupation determinations by APFIM for Hf, Fe, and Co in Ni3Al, Scripta Mater. 20 (1986) 1125-1130.

[23] Y.L. Hao, R. Yang, Y. Song, Y.Y. Cui, D. Li, M. Niinomi, Concentration of Point Defects and Site Occupancy Behavior in Ternary NiAl Alloys, Mater. Sci. Eng. A. 365 (2004) 85-89.

[24] G. Bozzolo, R.D. Noebe, F. Honecy, Modeling of ternary element site substitution in NiAl, Intermetallics 8 (2000) 7-18.

[25] C.R. Kao, L.M. Pike, S.-. Chen, Y.A. Chang, Site preference of substitutional additions to tripledefect B2 intermetallic compounds, Intermetallics 2 (1994) 235-247.

[26] C. Jiang, Site preference of transition-metal elements in B2 NiAl: A comprehensive study, Acta Mater. 55 (2007) 4799-4806.

[27] M. Balasubramanian, D.M. Pease, J.I. Budnick, T. Manzur, D.L. Brewe, Site-occupation tendencies for ternary additions (Fe, Co, Ni) in $\beta$-phase transition-metal aluminides, Phys. Rev. B 51 (1995) 8102.

[28] Y. Terada, K. Ohkubo, T. Mohri, T. Suzuki, Site preference in NiAl-determination by thermal conductivity measurement, Mater. Sci. Eng. A 329-331 (2002) 468-473.

[29] V. Raghavan, Al-Co-Ni (Aluminum-Cobalt-Nickel), J. Phase Equilib. 27 (2006) 372-380.

[30] C.Y. Geng, C.Y. Wang, T. Yu, Site preference and alloying effect of platinum group metals in $\gamma^{\prime}-$ Ni3Al, Acta Mater. 52 (2004) 5427-5433.

[31] V. Raghavan, Al-Ni-Pt (Aluminum-Nickel-Platinum), J. Phase Equilib. 27 (2006) 497-498.

[32] A. Chiba, D. Shindo, S. Hanada, Site occupation determination of Pd in Ni3Al by ALCHEMI, Acta Metall. 39 (1991) 13-18.

[33] M. Daniel, M. Balasubramanian, D. Brewe, M.J. Mehl, D. Pease, J.I. Budnick, Site selectivity and bonding in the B-phase aluminides: Studies of RuAl, PdAl, and Pd and Ru dopants in NiAl, Phys. Rev. B 61 (2000) 6637-6644. 
[34] A.P. Ofori, C.J. Rossouw, C.J. Humphreys, Determining the site occupancy of Ru in the L12 phase of a Ni-base superalloy using ALCHEMI, Acta Mater. 53 (2005) 97-110.

[35] V. Raghavan, Al-Ni-Ru (Aluminum-Nickel-Ruthenium), J. Phase Equilib. 29 (2008) 280-281.

[36] B. Tryon and T.M. Pollock, Experimental assessment of the Ru-Al-Ni ternary phase diagram at 1000 and 1100 deg C, Mater. Sci. Eng. A 430 (2006) 266-276.

[37] V. Raghavan, Al-Ir-Ni (Aluminum-Iridium-Nickel), J. Phase Equilib. 29 (2008) 61-61.

[38] G. Frommeyer, R. Fischer, J. Deges, R. Rablbauer, A. Schneider, APFIM investigations on site occupancies of the ternary alloying elements $\mathrm{Cr}, \mathrm{Fe}$, and Re in NiAl, Ultramicroscopy 101 (2004) 139-148.

[39] V. Raghavan, Al-Ni-Re (Aluminum-Nickel-Rhenium), J. Phase Equilib. 27 (2006) 499-500.

[40] A. Almazouzi, H. Numakura, M. Koiwa, K. Hono, T. Sakurai, Site occupation preference of Fe in Ni3Al: an atom-probe study, Intermetallics 5 (1997) 37-43.

[41] N.I. Medvedeva, Y.N. Gornostyrev, D.L. Novikov, O.N. Mryasov, A.J. Freeman, Ternary site preference energies, size misfits and solid solution hardening in NiAl and FeAl, Acta Mater. 46 (1998) 3433-3442.

[42] C.L. Fu and J. Zou, Site preference of ternary alloying additions in FeAl and NiAl by first-principles calculations, Acta Mater. 44 (1996) 1471-1478.

[43] I.M. Anderson, A.J. Duncan, J. Bentley, Site-distributions of Fe alloying additions to B2-ordered NiAl, Intermetallics 7 (1999) 1017-1024.

[44] D. Golberg and A. Shevakin, Iron in NiAl intermetallic compound: atomic arrangements and associated magnetic properties and electronic structures, Intermetallics 3 (1995) 293-301.

[45] P. Chartier, M. Balasubramanian, D. Brewe, T. Manzur, D. Pease, J. Budnick, L. Huang, C. Law, S. Russell, C. Kimball, Site selectivity in Fe doped ß phase NiAl, J. Appl. Phys. 75 (1994) 3842-3846.

[46] A.J. Duncan, M.J. Kaufman, C.T. Liu, M.K. Miller, Site occupation of iron in intermetallic NiAl, Appl. Surf. Sci. 76-77 (1994) 155-159.

[47] V. Raghavan, Al-Fe-Ni (Aluminum-Iron-Nickel), J. Phase Equilib. 27 (2006) 489-490.

[48] I. Chumak, K.W. Richter, H. Ipser, The Fe-Ni-Al phase diagram in the Al-rich ( > 50at.\% Al) corner, Intermetallics 15 (2007) 1416-1424.

[49] C.H. Liebscher, J. Preussner, R. Voelkl, U. Glatzel, Atomic site location by channelling enhanced microanalysis (ALCHEMI) in $\gamma^{\prime}$-strengthened Ni- and Pt-base alloys, Acta Mater. 56 (2008) 4267-4276.

[50] C. Booth-Morrison, Z. Mao, R.D. Noebe, D.N. Seidman, Chromium and tantalum site substitution patterns in Ni3Al (L12) $\gamma^{\prime}$-precipitates, Appl. Phys. Lett. 93 (2008) 033103. 
[51] W.H. Tian, C.S. Han, M. Nemoto, Precipitation of $\alpha$-Cr in B2-ordered NiAl, Intermetallics 7 (1999) 59-67.

[52] V. Raghavan, Al-Cr-Ni (Aluminum-Chromium-Nickel), J. Phase Equilib. 30 (2009) 61-63.

[53] D. Golberg and A. Shevakin, The effect of manganese on magnetic properties and atomic and electronic structure of NiAl intermetallic compounds, Intermetallics 2 (1994) 147-153.

[54] V. Raghavan, Al-Mn-Ni (Aluminum-Manganese-Nickel), J. Phase Equilib. 27 (2006) 493-496.

[55] A.W. Wilson and J.M. Howe, Statistical alchemi study of the site occupancies of Ti and Cu in NiAl, Scr. Mater. 41 (1999) 327-331.

[56] P. Kitabjian, A. Garg, R. Noebe, High-temperature deformation behavior of NiAl (Ti) solid-solution single crystals, Metall. Mater. Trans. A 30 (1999) 587-600.

[57] V. Raghavan, Al-Ni-Ti (Aluminum-Nickel-Titanium), J. Phase Equilib. 30 (2009) 77-78.

[58] V. Raghavan, Al-Ni-Ta (aluminum-nickel-tantalum), J. Phase Equilib. 27 (2006) 405-407.

[59] V. Raghavan, Al-Ni-Si (Aluminum-Nickel-Silicon), J. Phase Equilib. 27 (2006) 505-506.

[60] P. Munroe and I. Baker, Effect of accelerating voltage on planar and axial channeling in ordered intermetallic compounds, J. Mater. Res. 7 (1992) 2119-2125.

[61] V. Raghavan, Al-Hf-Ni (Aluminum-Hafnium-Nickel), J. Phase Equilib. 30 (2009) 64-66.

[62] Y.H. Sohn, J.H. Kim, E.H. Jordan, M. Gell, Thermal cycling of EB-PVD/MCrAlY thermal barrier coatings: I. Microstructural development and spallation mechanisms, Surf. Coat. Technol. 146-147 (2001) 70-78.

[63] R. Mévrel, State of the art on high-temperature corrosion-resistant coatings, Mater. Sci. Eng. A 120121, Part 1 (1989) 13-24.

[64] J.R. Davis, Heat-Resistant Materials, ASM International, Member/Customer Service Center, Materials Park, OH 44073-0002, USA, 1997.

[65] J.K. Tien and F.S. Pettit, Mechanism of oxide adherence on Fe-25Cr-4Al (Y or Sc) alloys, Metall. Mater. Tran. B 3 (1972) 1587-1599.

[66] J.G. Smeggil, A.W. Funkenbusch, N.S. Bornstein, A Relationship between Indigenous Impurity Elements and Protective Oxide Scale Adherence Characteristics, Metall. Trans. A. 17A (1986) 923-932.

[67] T.J. Nijdam and W.G. Sloof, Effect of Y distribution on the oxidation kinetics of NiCoCrAlY bond coat alloys, Oxid. Met. 69 (2008) 1-12.

[68] D.P. Moon, Role of Reactive Elements in Alloy Protection, Mater. Sci. Tech. 5 (1989) 754-764. 
[69] W.G. Sloof and T.J. Nijdam, On the high-temperature oxidation of MCrAlY coatings, Int. J. Mater. Rsych. 100 (2009) 1318-1330.

[70] M. Le Gall, A. Huntz, B. Lesage, C. Monty, J. Bernardini, Self-diffusion in $\alpha$-Al2O3 and growth rate of alumina scales formed by oxidation: effect of Y2O3 doping, J. Mater. Sci. 30 (1995) 201-211.

[71] T. Matsudaira, M. Wada, S. Kitaoka, Effect of Dopants on the Distribution of Aluminum and Oxygen Fluxes in Polycrystalline Alumina Under Oxygen Potential Gradients at High Temperatures, J. Am.

Ceram. Soc. 96 (2013) 3243-3251.

[72] B. Pint, K. More, I. Wright, Effect of quaternary additions on the oxidation behavior of Hf-doped NiAl, Oxid. Met. 59 (2003) 257-283.

[73] B.A. Pint, Optimization of reactive-element additions to improve oxidation performance of aluminaforming alloys, J. Am. Ceram. Soc. 86 (2003) 686-695.

[74] P. Bellina, A. Catanoiu, F. Morales, M. Ruhle, Formation of discontinuous Al2O3 layers during hightemperature oxidation of RuAl alloys, J. Mater. Res. 21 (2006) 276-286.

[75] Z.B. Bao, H. Murakami, Y. Yamabe-Mitarai, Effects of thermal exposure on Ir-based alloys with and without Pt coating, Corros. Sci. 53 (2011) 1224-1229. 


\section{Tables and figures.}

Table I. Nominal compositions of the HVOF coatings (in weight percent).

\begin{tabular}{|l|r|r|r|r|r|r|r|r|r|r|r|r|r|r|r|}
\hline Alloys & $\mathrm{Ni}$ & $\mathrm{Co}$ & $\mathrm{Cr}$ & $\mathrm{Al}$ & $\mathrm{Y}$ & $\mathrm{Si}$ & $\mathrm{Ta}$ & $\mathrm{Ir}$ & $\mathrm{Ru}$ & $\mathrm{Hf}$ & $\mathrm{Mo}$ & $\mathrm{Ti}$ & $\mathrm{W}$ & $\mathrm{C}$ & $\mathrm{Zr}+\mathrm{B}$ \\
\hline A0 & Bal. (44.85) & 28 & 15 & 11 & 0.4 & 0.25 & 0.5 & & & & & & & & \\
\hline A1 & Bal. (43.85) & 28 & 15 & 11 & 0.4 & 0.25 & 0.5 & & 0.5 & & 0.5 & & & & \\
\hline A2 & Bal. (44.35) & 28 & 15 & 11 & 0.4 & 0.25 & 0.5 & 0.5 & & & & & & & \\
\hline B0 & 30 & Bal. (38.9) & 20 & 10 & 0.6 & 0.5 & & & & & & & & & \\
\hline B1 & 30 & Bal. (37.9) & 20 & 10 & 0.6 & 0.5 & 0.5 & & 0.5 & & & & & & \\
\hline B2 & 30 & Bal. (38.4) & 20 & 10 & 0.6 & 0.5 & & 0.5 & & & & & & & \\
\hline B3 & 30 & Bal. (37.8) & 20 & 10 & 0.6 & 0.5 & & 0.05 & 0.25 & 0.3 & 0.5 & & & & \\
\hline substrate & Bal. (60.69) & 9 & 12.5 & 3.4 & & & 4.2 & & & & 1.9 & 4 & 4.2 & 0.08 & 0.03 \\
\hline
\end{tabular}




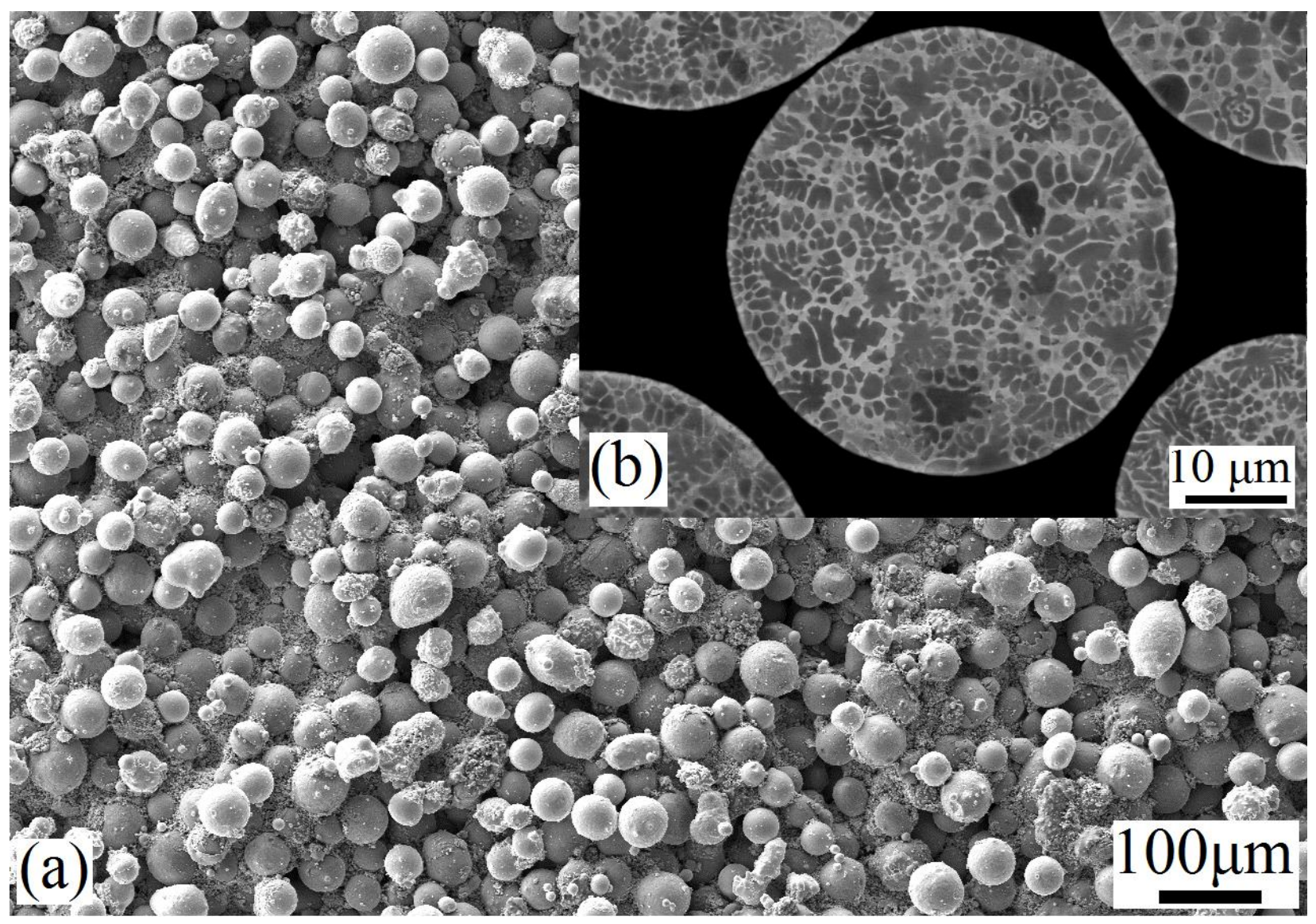

Figure 1. Powders used for the HVOF spray. (a) SE image showing the morphology of the powders, (b) BSE image showing the cross section of a powder. 


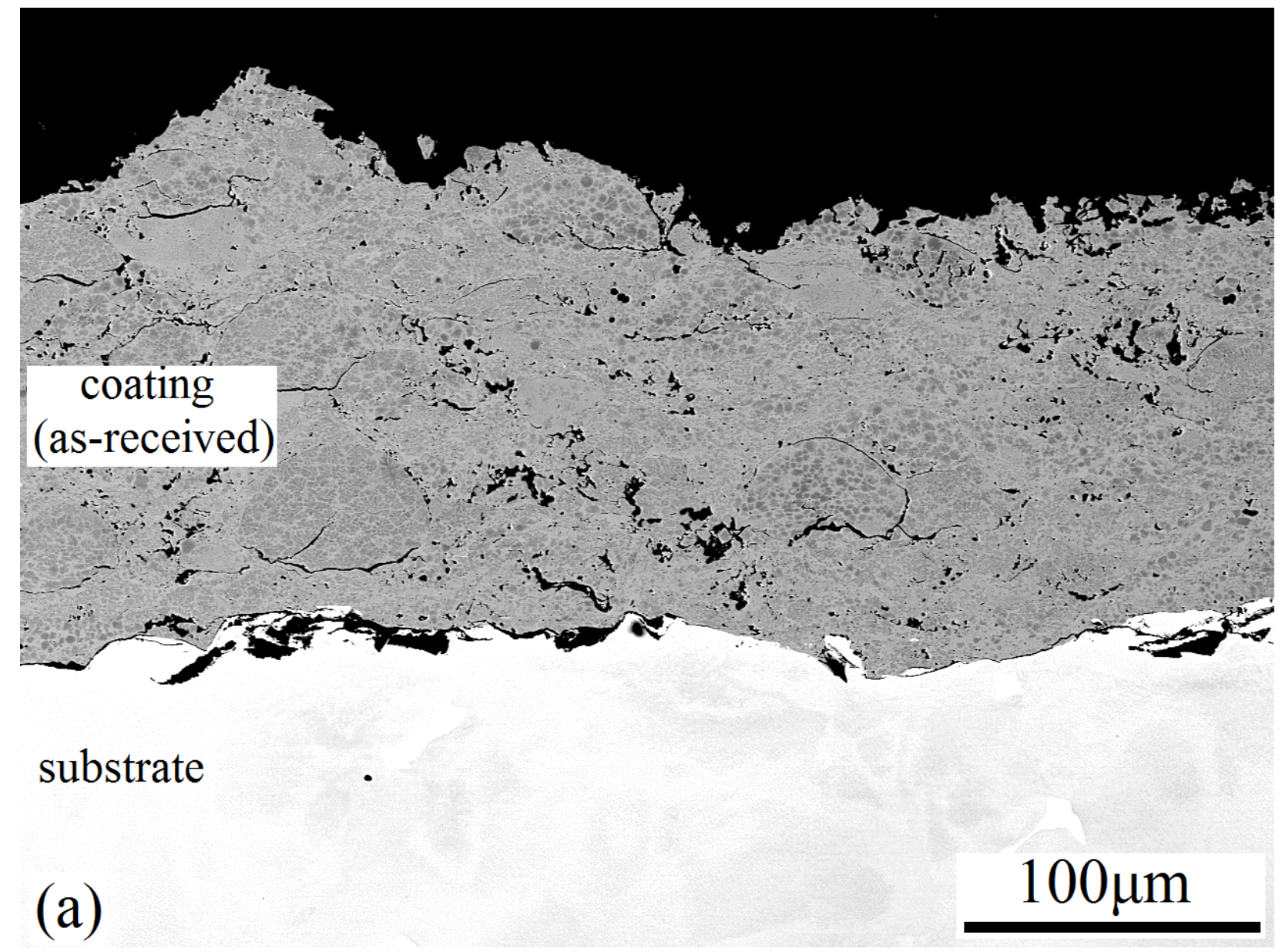




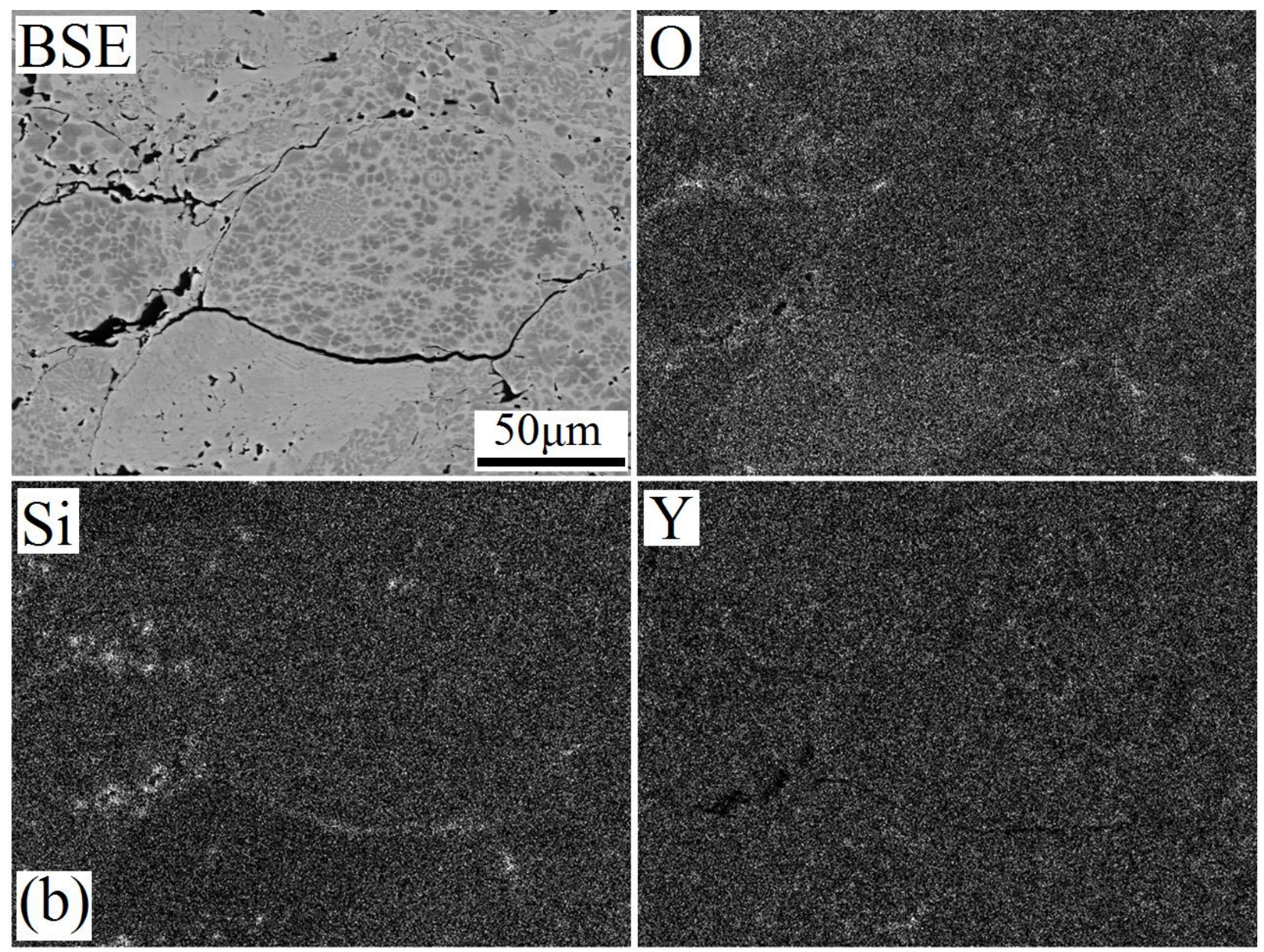

Figure 2. (a) BSE image showing the cross section of an as-received coating, (b) EDS mapping of O, Si and $\mathrm{Y}$ in the as received coating. The coating is A0. 


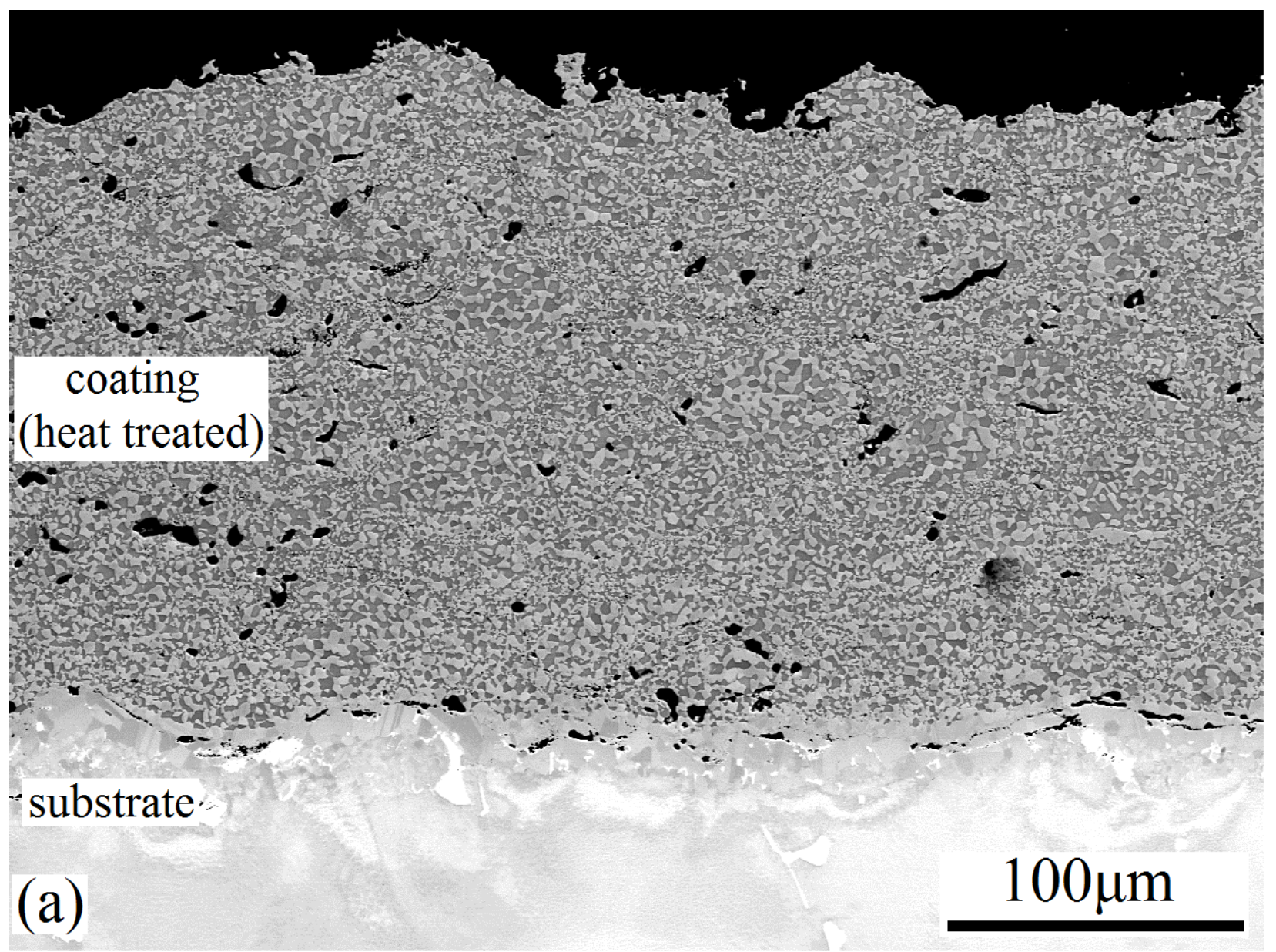




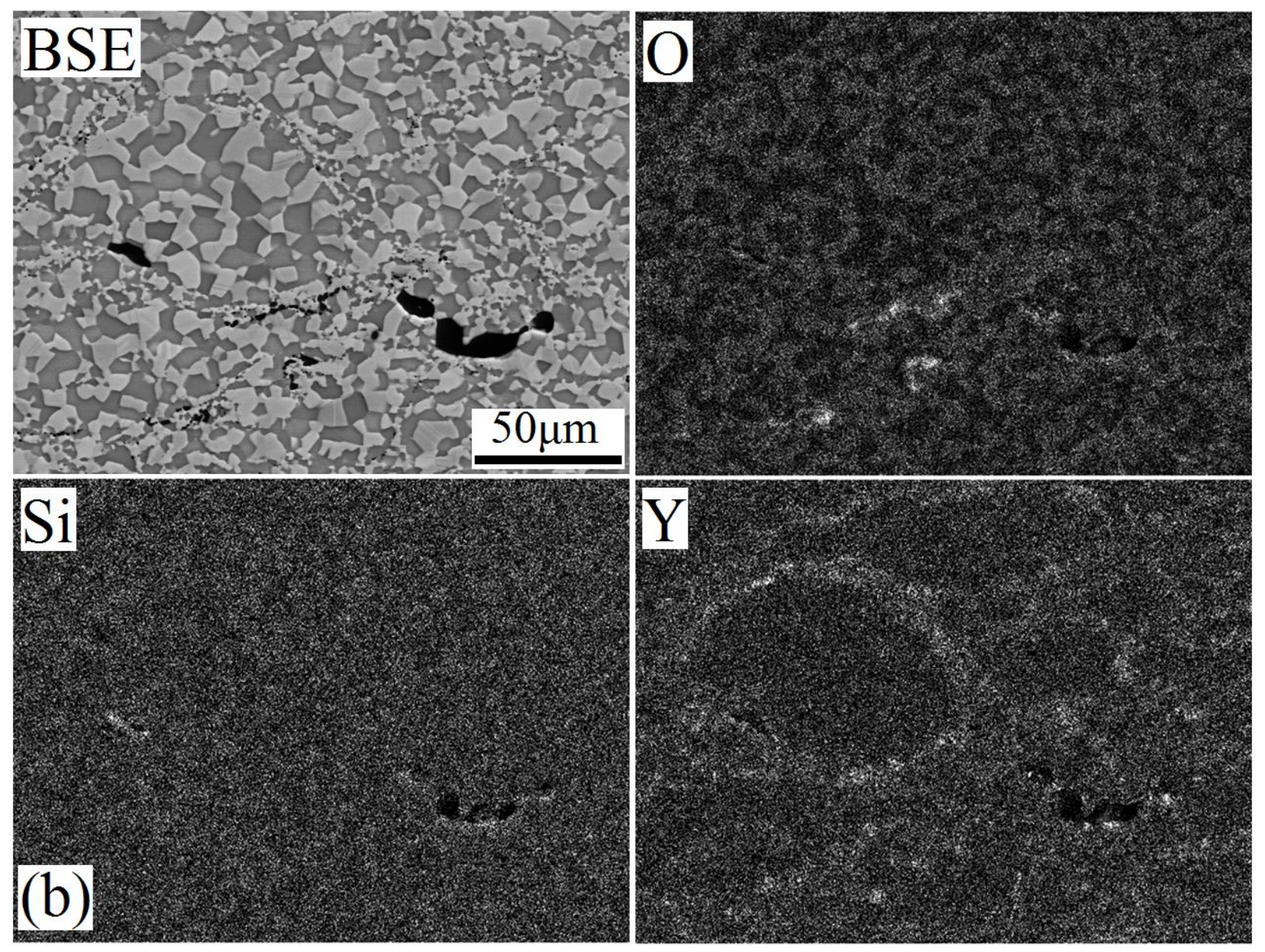

Figure 3. (a) BSE image showing the cross section of a coating after the heat treatment, (b) EDS mapping of $\mathrm{O}, \mathrm{Si}$ and $\mathrm{Y}$ in the coating. The coating is A0. 

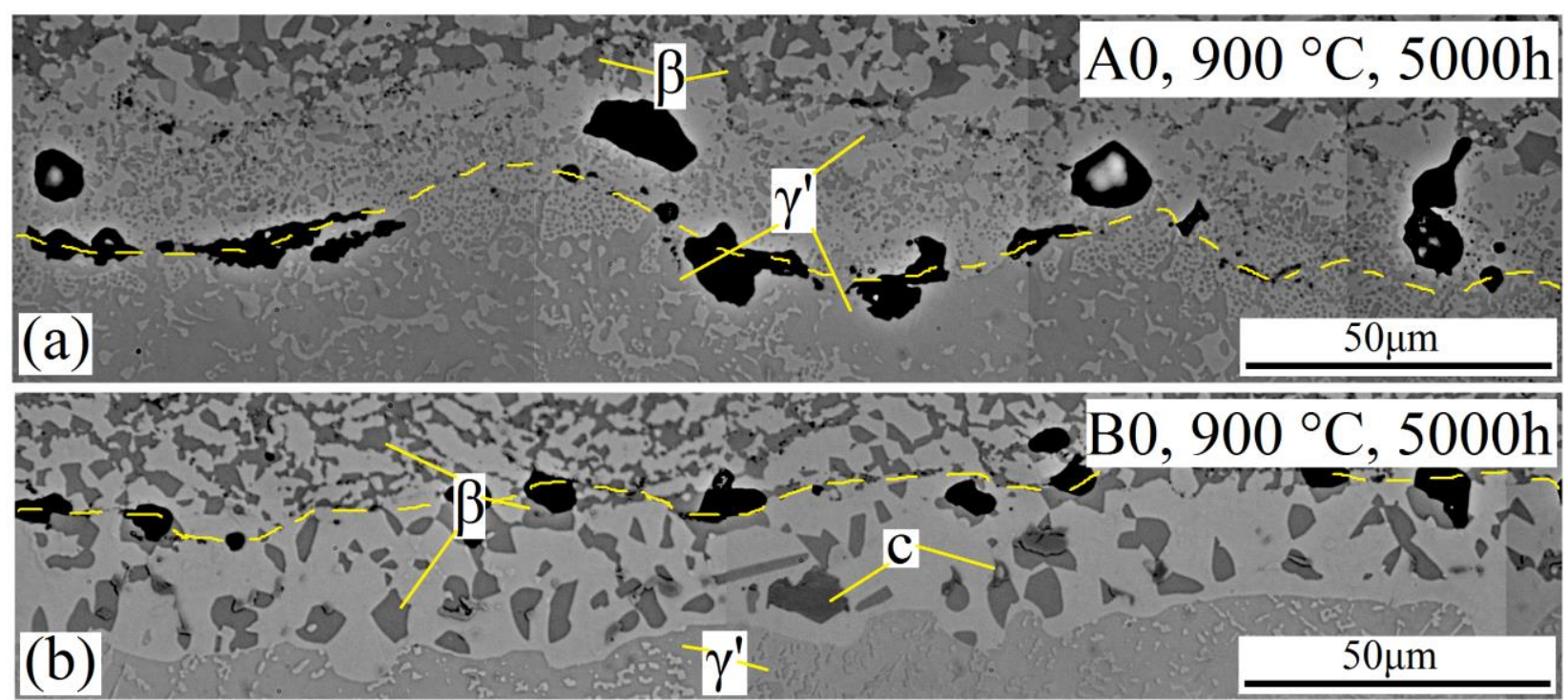

Figure 4. Microstructure near the interface (marked by dash curves) between the coating (upper part) and the substrate (lower part) due to the interdiffusion of elements. The oxidation is at $900{ }^{\circ} \mathrm{C}$ for 5000 hours in (a) A0 and (b) B0. "c" donates MC-type carbides rich of Ti and Ta. 

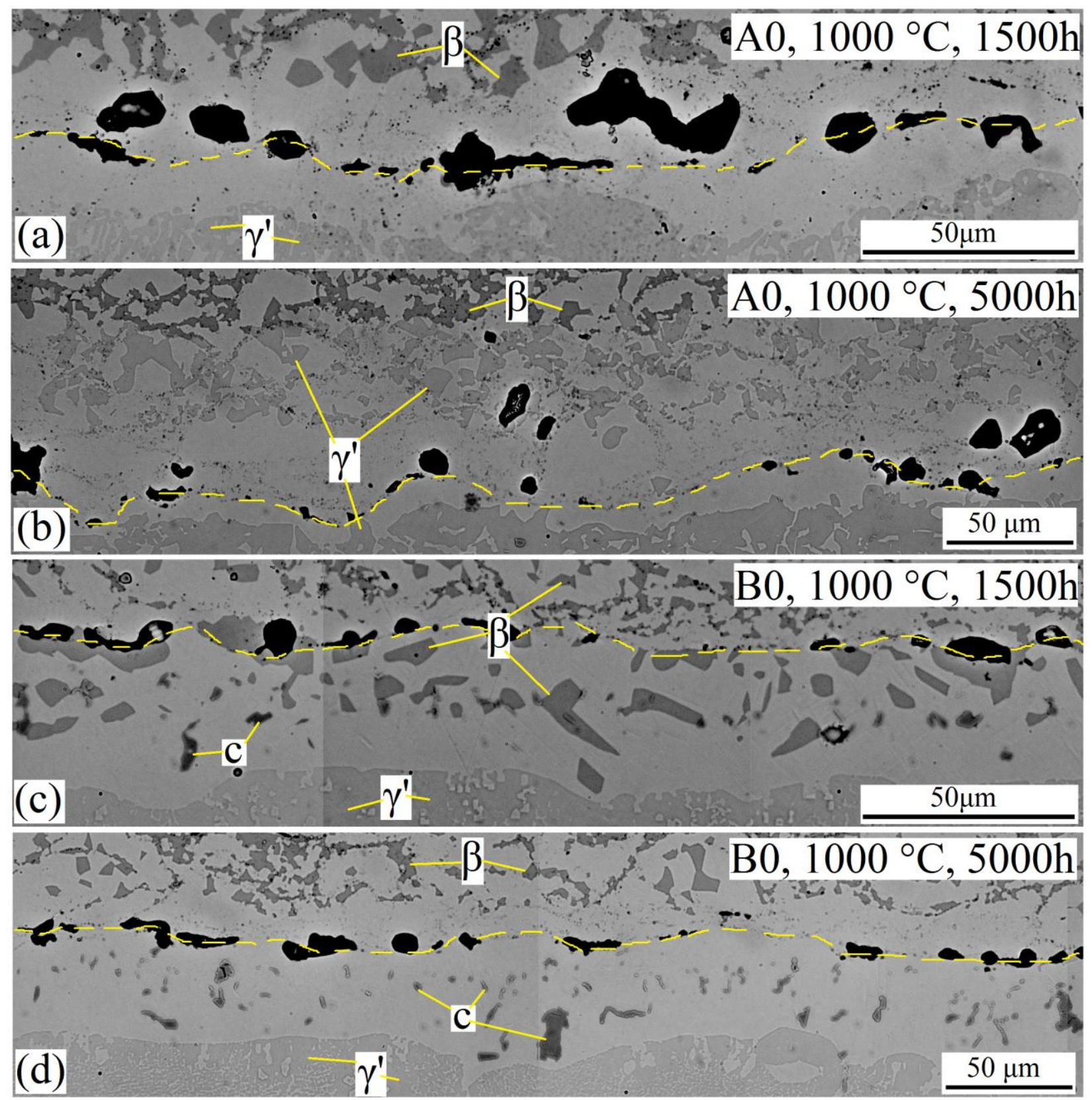

Figure 5. Microstructure near the interface (marked by dash curves) between the coating (upper part) and the substrate (lower part) due to the interdiffusion of elements. The oxidation is at $1000{ }^{\circ} \mathrm{C}$ : (a) for 1500 hours in A0, (b) for 5000 hours in A0, (c) for 1500 hours in B0, and (d) for 5000 hours in B0. "c" donates MC-type carbides rich of Ti and Ta. 


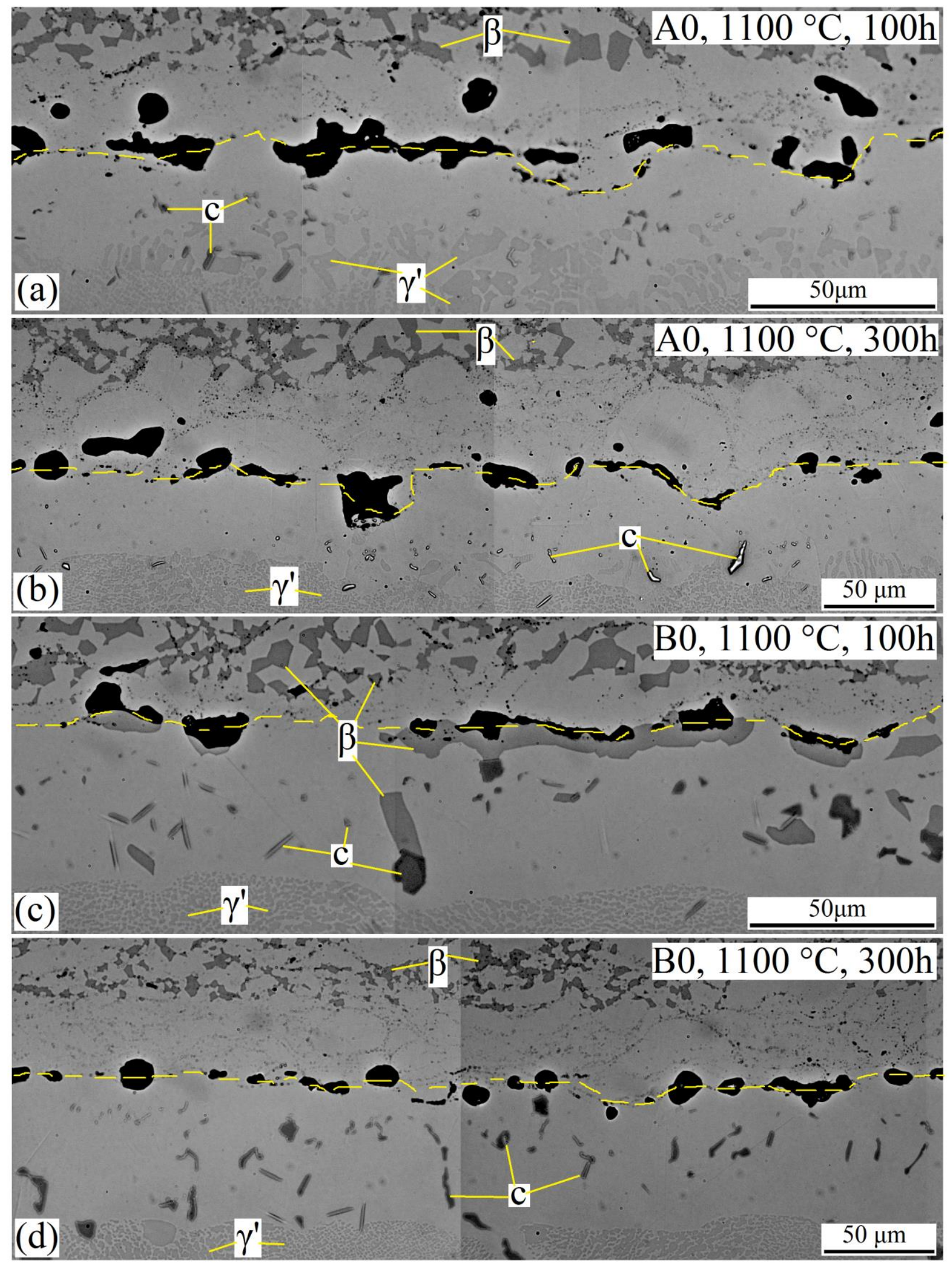


Figure 6. Microstructure near the interface (marked by dash curves) between the coating (upper part) and the substrate (lower part) due to the interdiffusion of elements. The oxidation was at $1100{ }^{\circ} \mathrm{C}$ : (a) for 100 hours in A0, (b) for 300 hours in A0, (c) for 100 hours in B0, and (d) for 300 hours in B0. "c" donates MC-type carbides rich of Ti and Ta. 


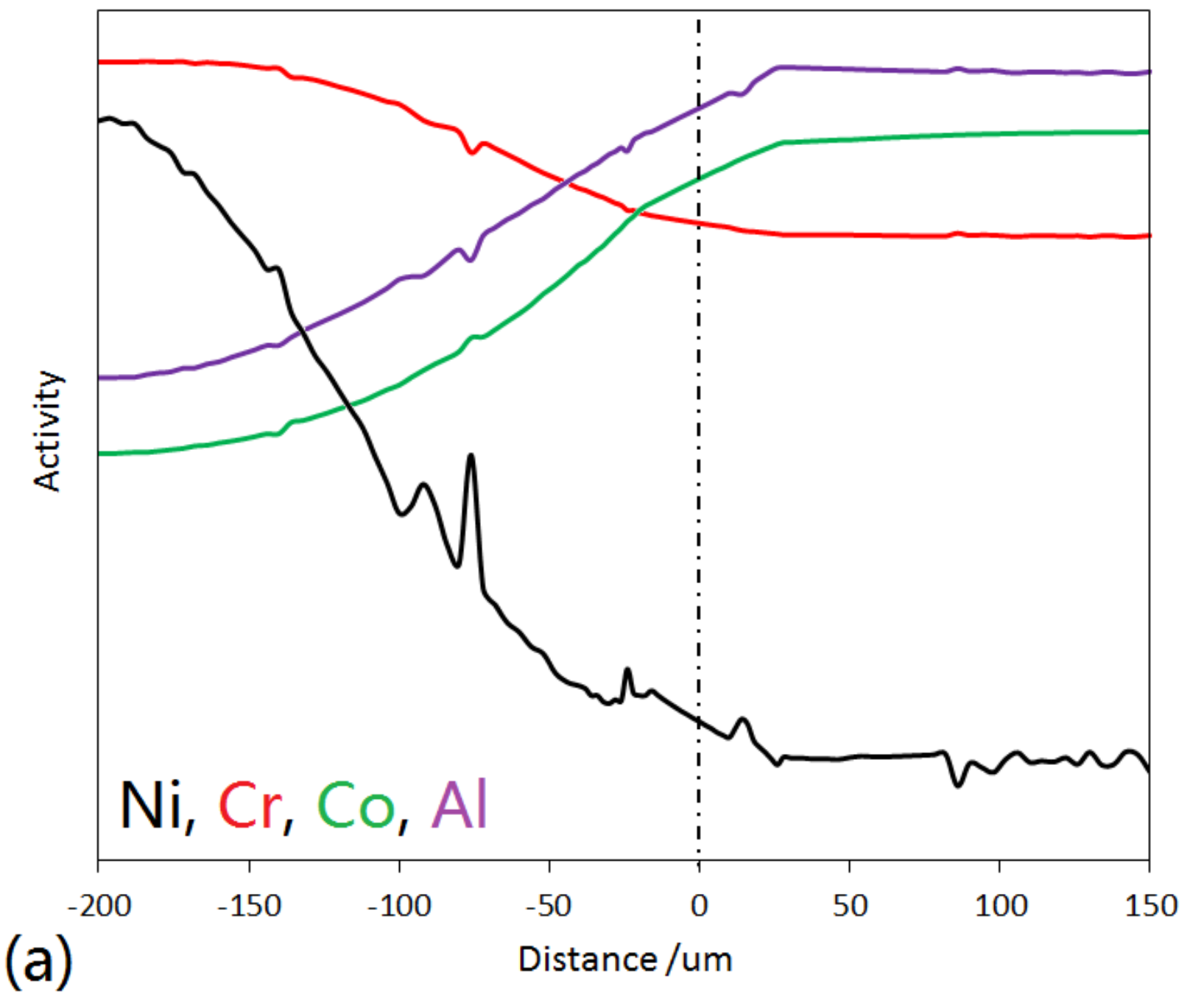




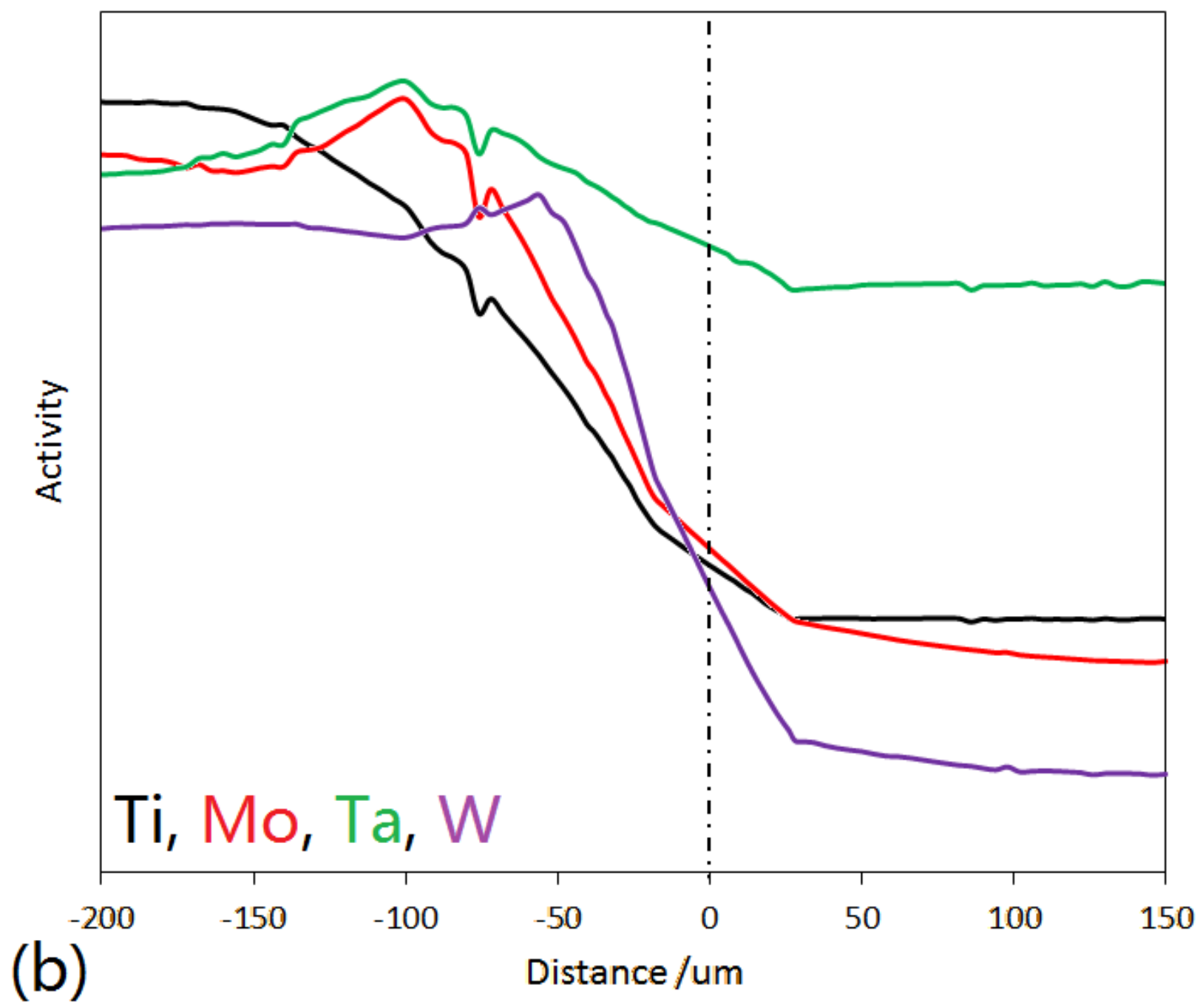

Figure 7. Activity profiles of the alloying elements in the A0-substrate system by the interdiffusion simulation (condition: $1100{ }^{\circ} \mathrm{C}, 1500$ hours), corresponding to the results in Fig. 8b. Distance $=0$ marks the coating-substrate interface, and the coating is on the right. The activity profiles are only showing their shapes, not exact values. 

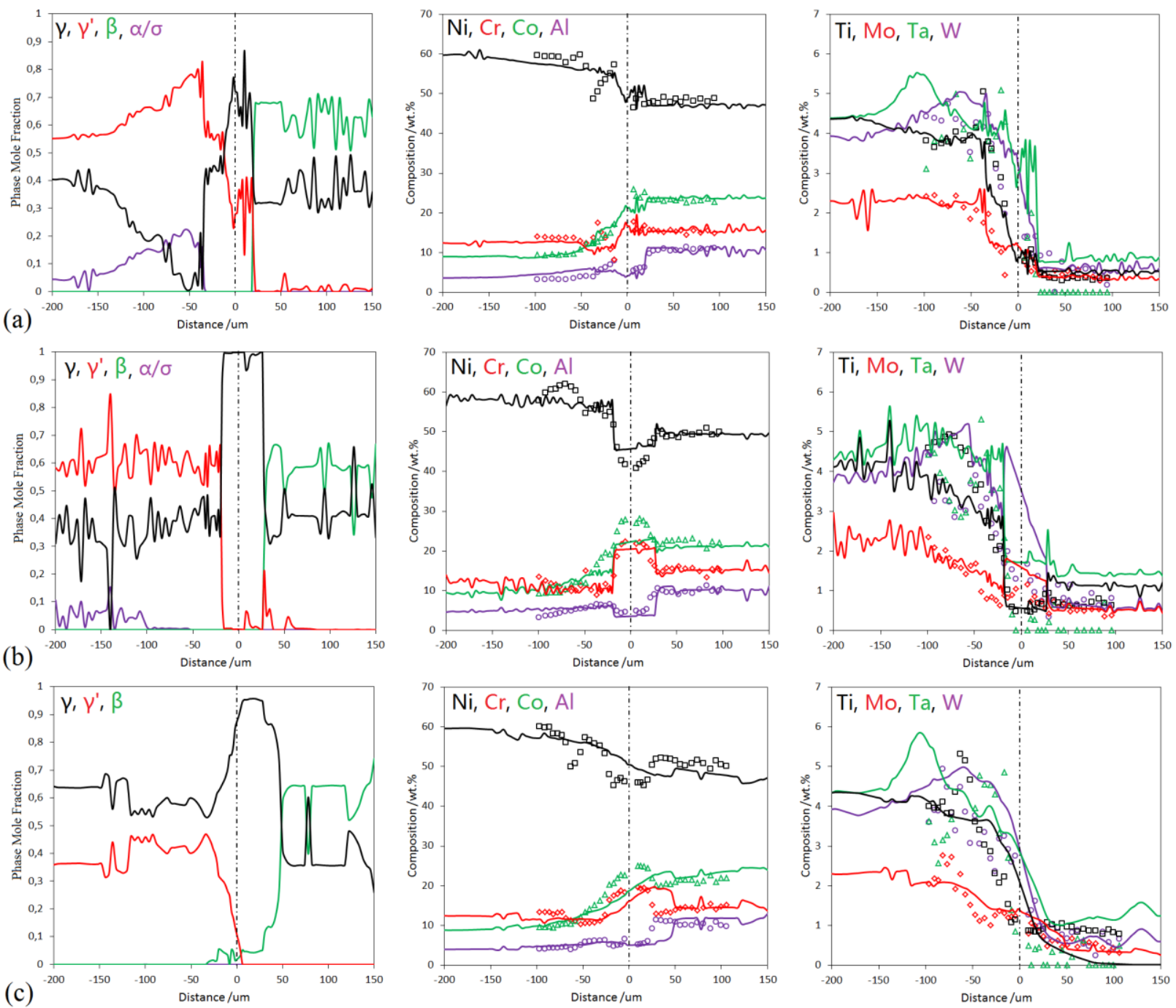

Figure 8. Profiles of phase fractions and elemental compositions by simulation (curves) and experiment (dots) in the A0-substrate system after the interdiffusion (a) at $900{ }^{\circ} \mathrm{C}$ for 5000 hours, (b) at $1000{ }^{\circ} \mathrm{C}$ for 1500 hours, and (c) at $1100{ }^{\circ} \mathrm{C}$ for 100 hours. Distance $=0$ marks the coating-substrate interface, and the coating is on the right. The curves and dots in color should be corresponded with the phases or the elements with the same color in each graph. The fluctuations on the profile curves, particularly on the phase-profile curves, are due to the numerical instability of the calculations by DICTRA software. 

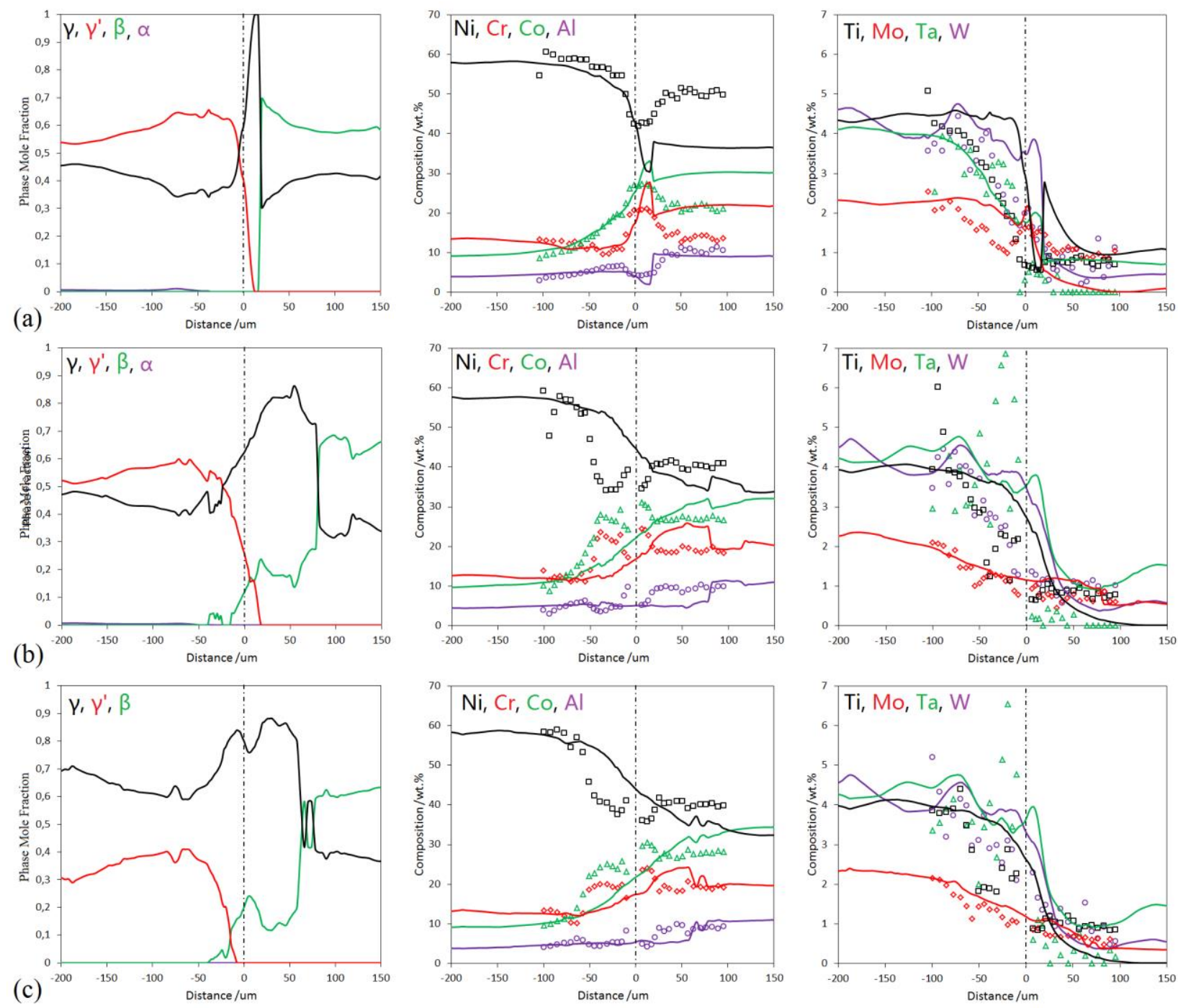

Figure 9. Profiles of phase fractions and elemental compositions by simulation (curves) and experiment (dots) in B0-substrate system after the interdiffusion (a) at $900{ }^{\circ} \mathrm{C}$ for 5000 hours, (b) at $1000{ }^{\circ} \mathrm{C}$ for 1500 hours, and (c) at $1100{ }^{\circ} \mathrm{C}$ for 100 hours. Distance $=0$ marks the coating-substrate interface, and the coating is on the right. The curves and dots in color should be corresponded with the phases or the elements with the same color in each graph. 


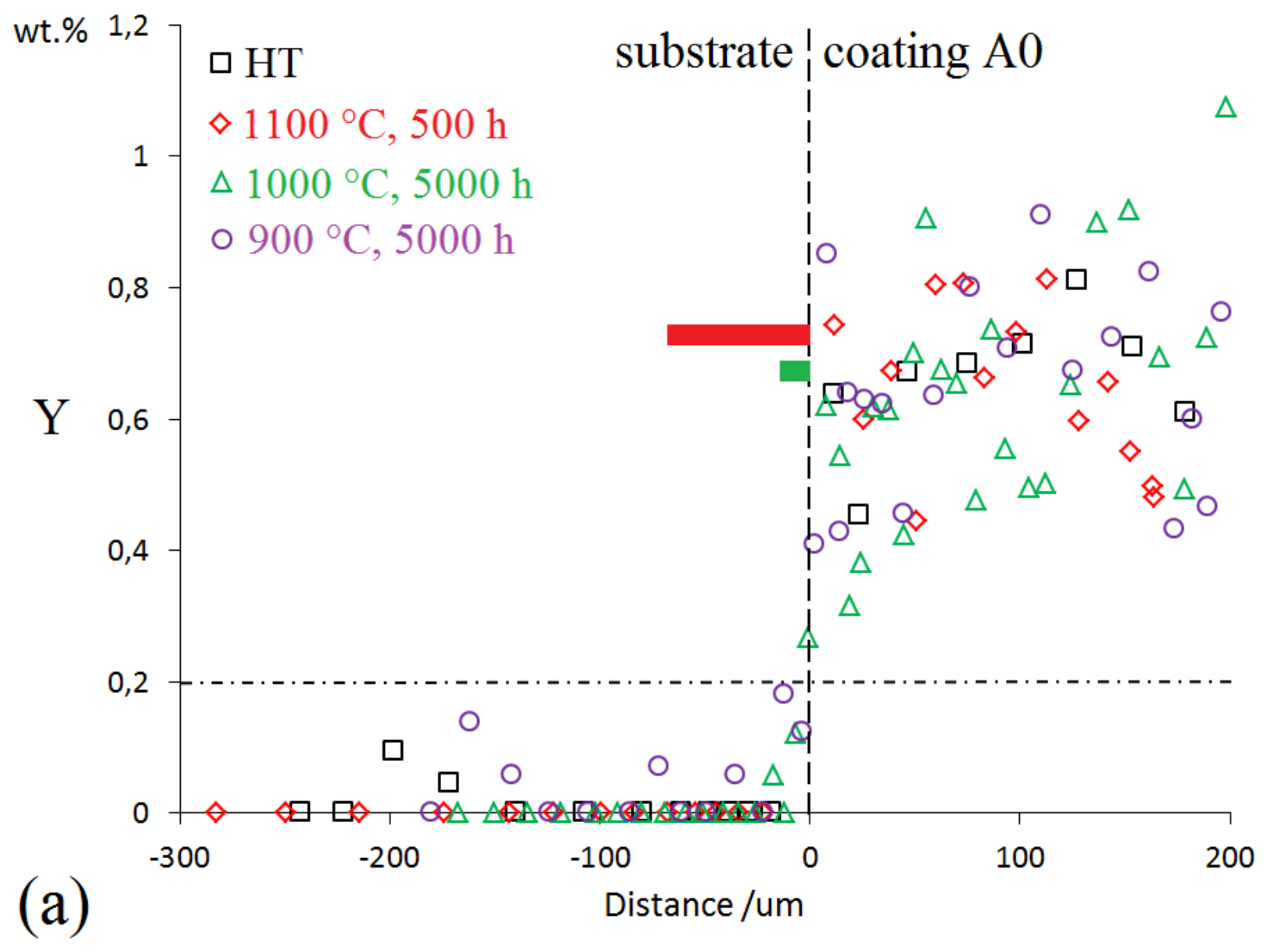




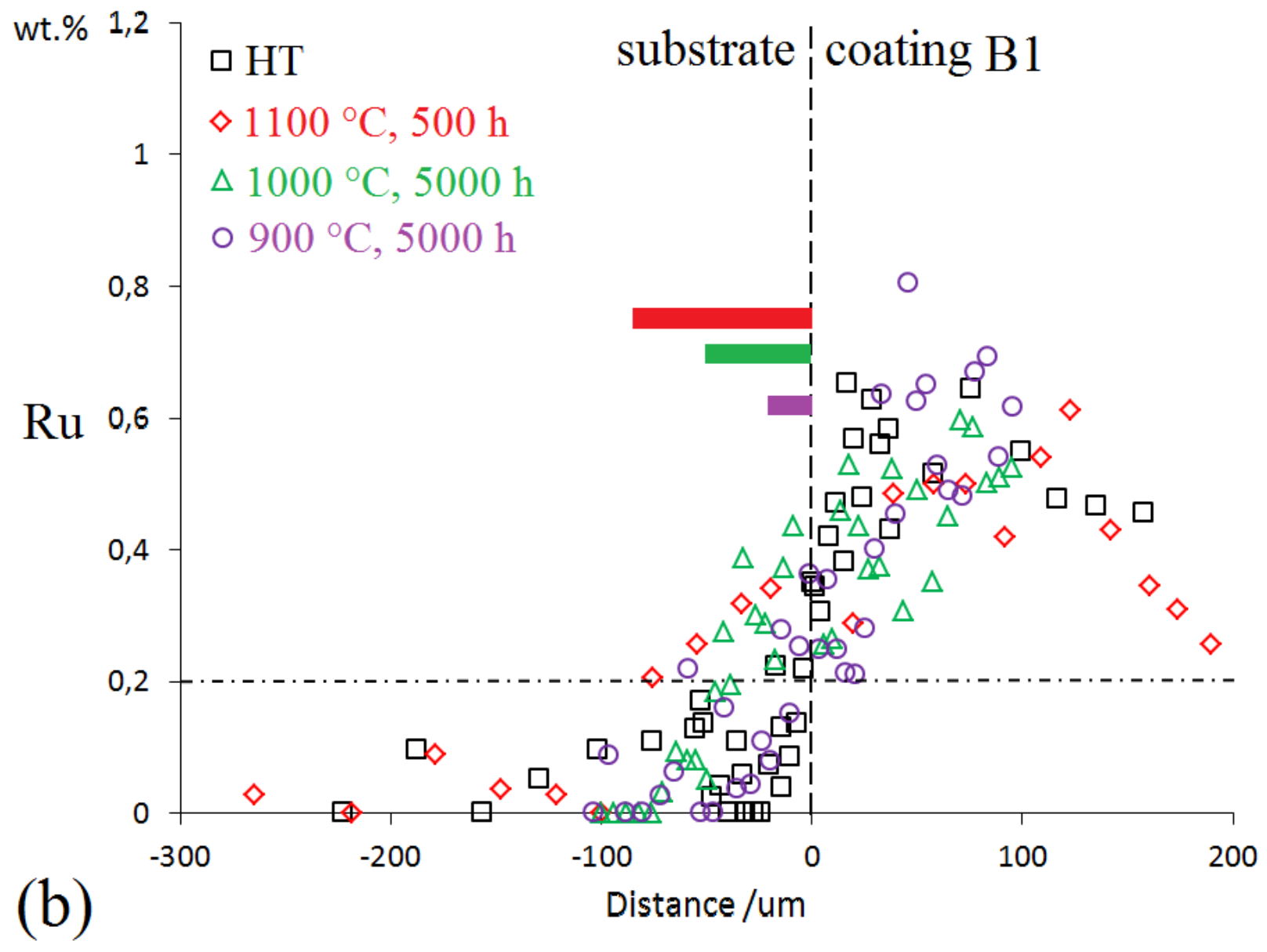




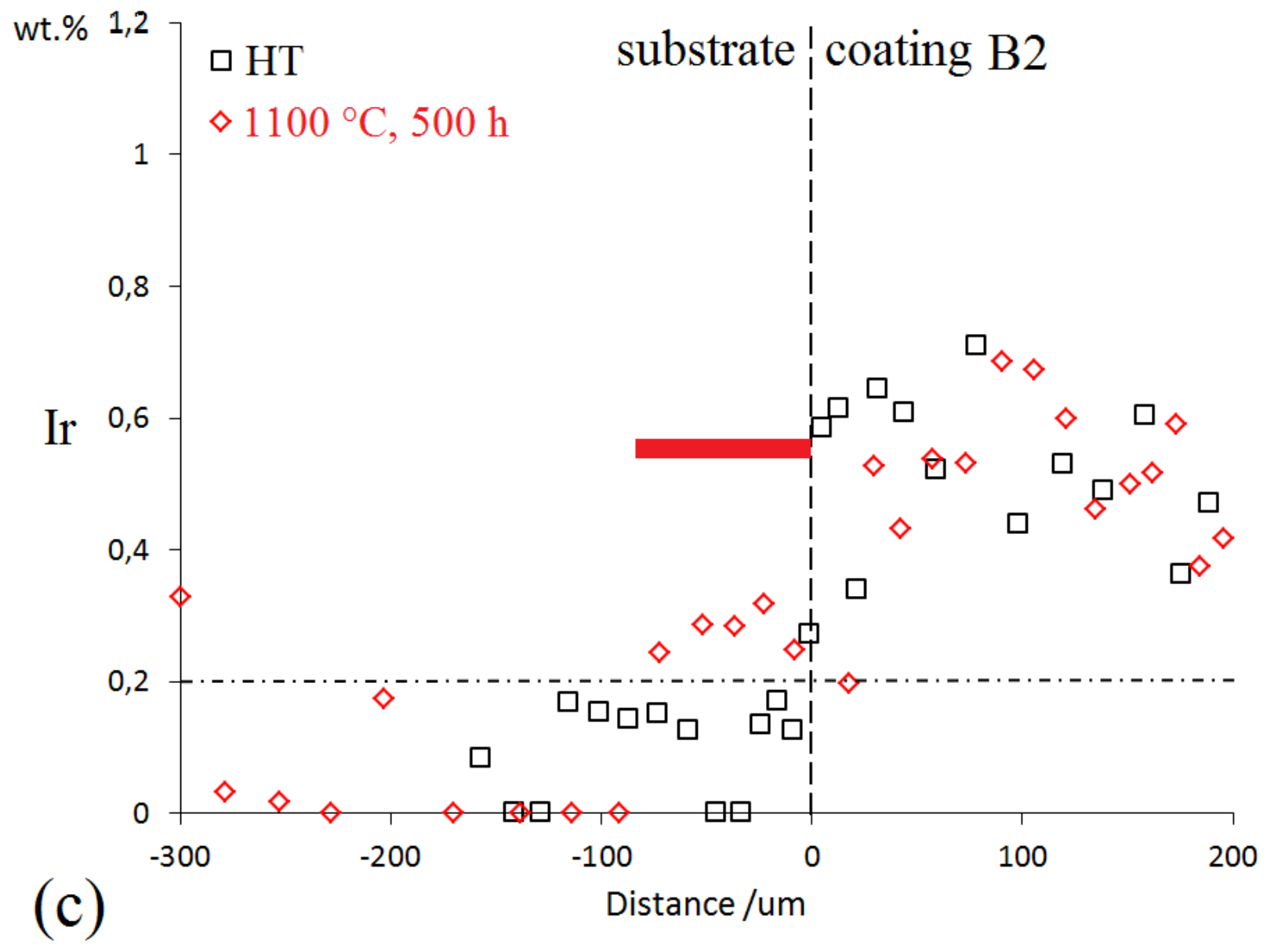

Figure 10. Compositions of $\mathrm{Y}, \mathrm{Ru}$ and $\mathrm{Ir}$ in some samples measured by EDS. The solid bars from the CSI to the substrate stand for the $\gamma^{\prime}$-depletion zone. The colors should be corresponded to the relevant oxidation conditions. 


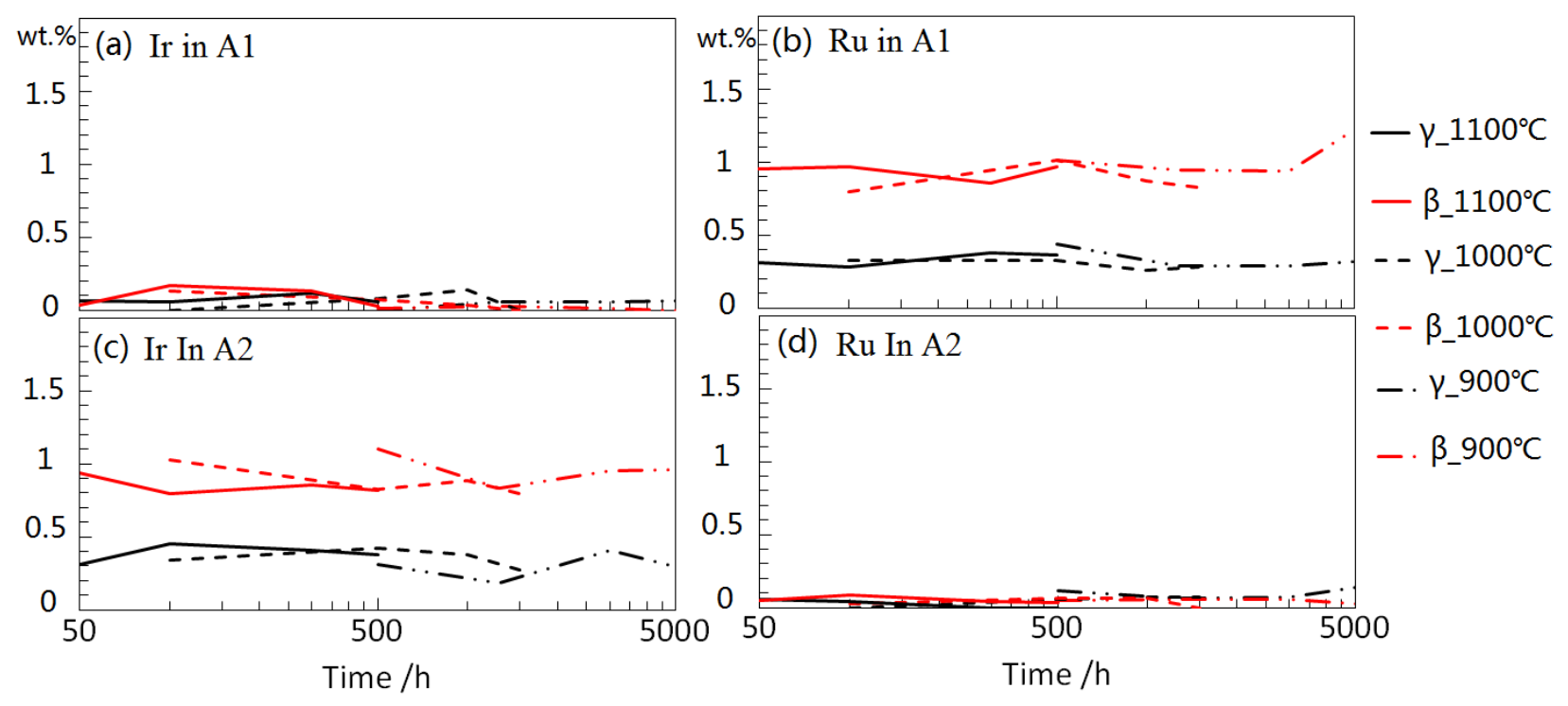

Figure 11. Solid solution content of Ir and Ru in coating A1 and A2 during oxidation processes, showing the dissolution of these two elements in $\gamma$ and $\beta$ phases near coating surfaces [17]. 
Table II. Summary of the site preference of alloying elements $\mathrm{X}$ in Ni-Al-X systems for the $\gamma^{\prime}-\mathrm{Ni} 3 \mathrm{Al}$ and $\beta$-NiAl phases. The calculation ("calc") or experimental ("exp") results are mainly for high temperatures at about $800-1300{ }^{\circ} \mathrm{C}$ (in some references temperature effect is not considered). The results are mainly for the case when small amount of an $\mathrm{X}$ element is added to replace $\mathrm{Ni}$ or $\mathrm{Al}$ in the chemical formulas of $\mathrm{Ni}_{3} \mathrm{Al}$ or $\mathrm{NiAl}$.

\begin{tabular}{|c|c|c|c|}
\hline Elements & Site preference in $\gamma^{\prime}-\mathrm{Ni}_{3} \mathrm{Al}$ phase & Site preference in $\beta$-NiAl phase & $\begin{array}{l}\text { Ref. for phase } \\
\text { diagrams }\end{array}$ \\
\hline $\mathrm{Co}$ & $\begin{array}{l}\text { (calc) slightly Ni site [19]; } \\
\text { (calc) composition dependent [20]; } \\
\text { (exp) Ni site }[21,22]\end{array}$ & $\begin{array}{l}\text { (calc) Ni site [23-26]; } \\
\text { (exp) Ni site }[27,28]\end{array}$ & {$[29]$} \\
\hline $\mathrm{Pt}$ & (calc) Ni site $[20,30]$ & $\begin{array}{l}\text { (calc) Ni site [26]; } \\
\text { (exp) Ni site [28]; }\end{array}$ & {$[31]$} \\
\hline $\mathrm{Pd}$ & $\begin{array}{l}\text { (calc) Ni site [20,30]; } \\
\text { (exp) Ni site [32]. }\end{array}$ & $\begin{array}{l}\text { (calc) Ni site [26]; } \\
\text { (exp) Ni site [33]; }\end{array}$ & - \\
\hline $\mathrm{Ru}$ & $\begin{array}{l}\text { (calc) slightly Al site [19]; } \\
\text { (calc) Al site [20]; } \\
\text { (calc) Ni site [30]; } \\
\text { (exp) Al site }[15,34]\end{array}$ & $\begin{array}{l}\text { (calc) slightly Al site [24]; } \\
\text { (calc) Ni site [26]; } \\
\text { (exp) Ni site [28,33]; }\end{array}$ & {$[35,36]$} \\
\hline Ir & (calc) composition dependent [20]; & (calc) Ni site $[26,26]$; & [37] \\
\hline $\operatorname{Re}$ & $\begin{array}{l}\text { (calc) Al site [19]; } \\
\text { (exp) Al site [15]; }\end{array}$ & $\begin{array}{l}\text { (calc) Ni site [26]; } \\
\text { (exp) Ni site [38]; }\end{array}$ & [39] \\
\hline $\mathrm{Fe}$ & $\begin{array}{l}\text { (calc) Al site [20]; } \\
\text { (exp) slightly Al site [22]; } \\
\text { (exp) Al site when adding < 3-4 at.\% [40]; } \\
\text { (exp) composition dependent when adding > 3- } \\
4 \text { at.\% [40]; } \\
\text { (exp) composition dependent [21] }\end{array}$ & $\begin{array}{l}\text { (calc) Ni site }[23,41] \\
\text { (calc) slightly Ni site [26]; } \\
\text { (calc) slightly Al site [24,25]; } \\
\text { (calc) composition dependent [42]; } \\
\text { (exp) composition } \\
\text { dependent }[27,28,38,43,43-45] ; \\
\text { (exp) Al site[45,46]; }\end{array}$ & {$[47,48]$} \\
\hline $\mathrm{Cr}$ & $\begin{array}{l}\text { (calc) Al site [19]; } \\
\text { (exp) Al site }[21,49,50] ;\end{array}$ & $\begin{array}{l}\text { (calc) composition dependent [23]; } \\
\text { (calc) Al site [24,25,41]; } \\
\text { (calc) composition dependent [26]; } \\
\text { (exp) composition dependent [28]; } \\
\text { (exp) Al site [38,51]; }\end{array}$ & {$[52]$} \\
\hline $\mathrm{Mn}$ & (calc) Al site [20]; & $\begin{array}{l}\text { (calc) Ni site [23]; } \\
\text { (calc) composition dependent [26]; } \\
\text { (exp) Al site [28]; } \\
\text { (exp) composition dependent [53]; }\end{array}$ & {$[54]$} \\
\hline Mo & (calc) Al site $[19,30]$; & $\begin{array}{l}\text { (calc) composition dependent }[23,26] \text {; } \\
\text { (calc) Al site }[24,41] \text {; } \\
\text { (exp) Ni site [28]; }\end{array}$ & - \\
\hline $\mathrm{W}$ & (calc) Al site [19]; & $\begin{array}{l}\text { (calc) composition dependent [23,26]; } \\
\text { (calc) Al site [24]; }\end{array}$ & - \\
\hline $\mathrm{Ti}$ & $\begin{array}{l}\text { (calc) Al site [19]; } \\
\text { (exp) Al site [49]; }\end{array}$ & $\begin{array}{l}\text { (calc) Al site }[23-26,41] ; \\
\text { (exp.) Al site }[28,55,56] ;\end{array}$ & {$[57]$} \\
\hline $\mathrm{Ta}$ & $\begin{array}{l}\text { (calc) Al site [19]; } \\
\text { (exp) Al site [50]; }\end{array}$ & $\begin{array}{l}\text { (calc) Al site [23,24,26]; } \\
(\exp ) \mathrm{Ni} \text { site [28]; }\end{array}$ & {$[58]$} \\
\hline $\mathrm{Si}$ & - & (calc) $\mathrm{Al}$ site $[23,24] ;$ & [59] \\
\hline $\mathrm{Nb}$ & (calc) Al site preference [19]; & $\begin{array}{l}\text { (calc) Al site [23,24,26]; } \\
(\exp ) \mathrm{Ni} \text { site }[28]\end{array}$ & - \\
\hline Hf & $\begin{array}{l}\text { (calc) } \mathrm{Al} \text { site }[20] ; \\
\text { (exp) } \mathrm{Al} \text { site }[22,60] ;\end{array}$ & (calc) Al site $[23,24,26] ;$ & {$[61]$} \\
\hline $\mathrm{Zr}$ & (calc) $\mathrm{Al}$ site [20]; & (calc) Al site $[23,24,26,41] ;$ & - \\
\hline $\mathrm{V}$ & (calc) Al site [20]; & $\begin{array}{l}\text { (calc) Al site [23-26,41]; } \\
\text { (exp) Al site [60]; } \\
\text { (exp) Ni site [28]; }\end{array}$ & - \\
\hline $\mathrm{Y}$ & (calc) Al site [19]; & - & - \\
\hline
\end{tabular}




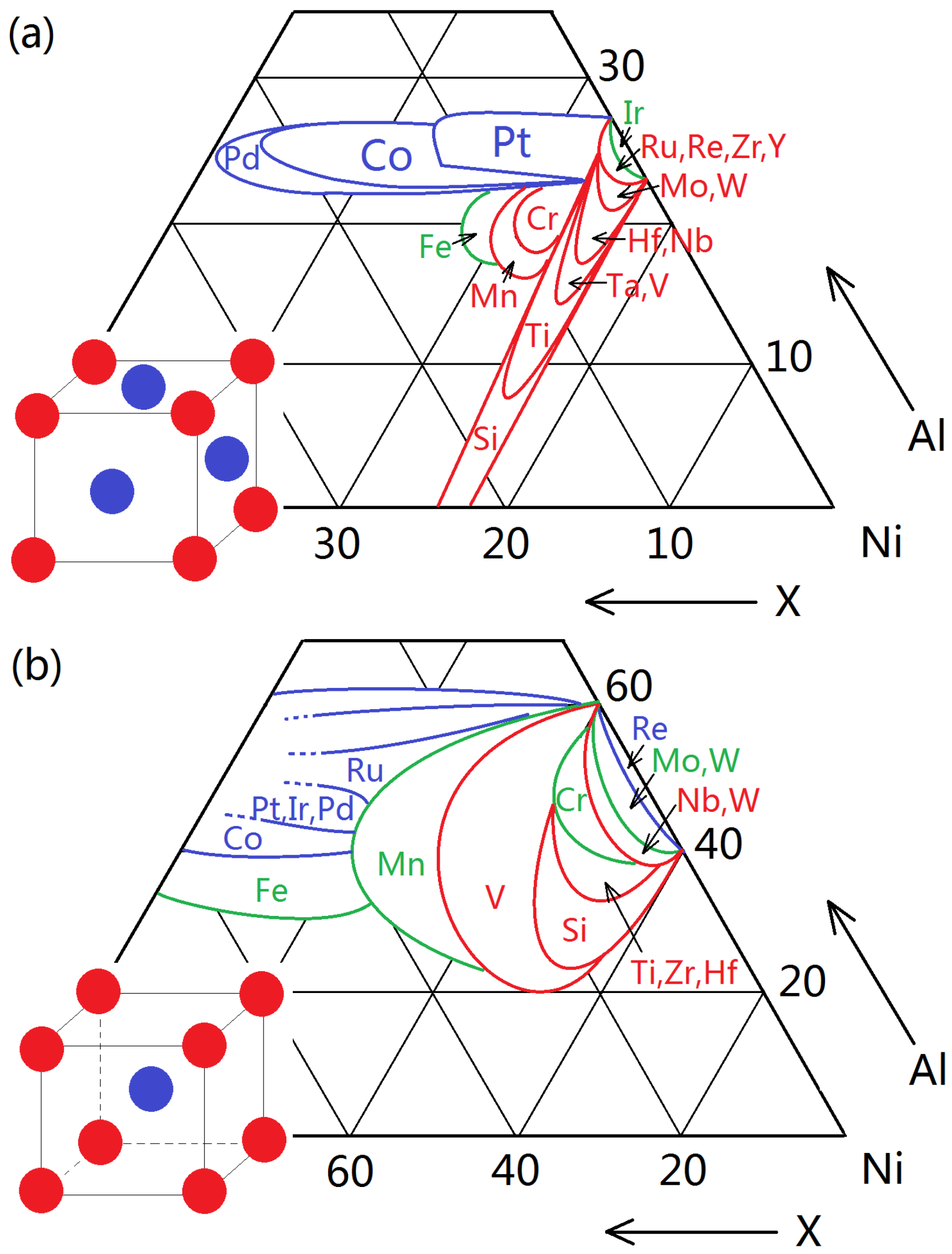


Figure 12. The effect of element $X$ on the extension of the fields of $\gamma^{\prime}$ phase (figure a) and $\beta$ phase (figure b) in the Ni-Al-X phase diagrams, showing the preferred site in the $\mathrm{Ni}_{3} \mathrm{Al}$ and $\mathrm{NiAl}$ cells (red for Al-site preference, blue for Ni-site preference and green for no strong preference). The site preference of the $\mathrm{X}$ elements and the phase-filed extension are based on the results in Table II and some calculations by using Thermo-Calc software. 


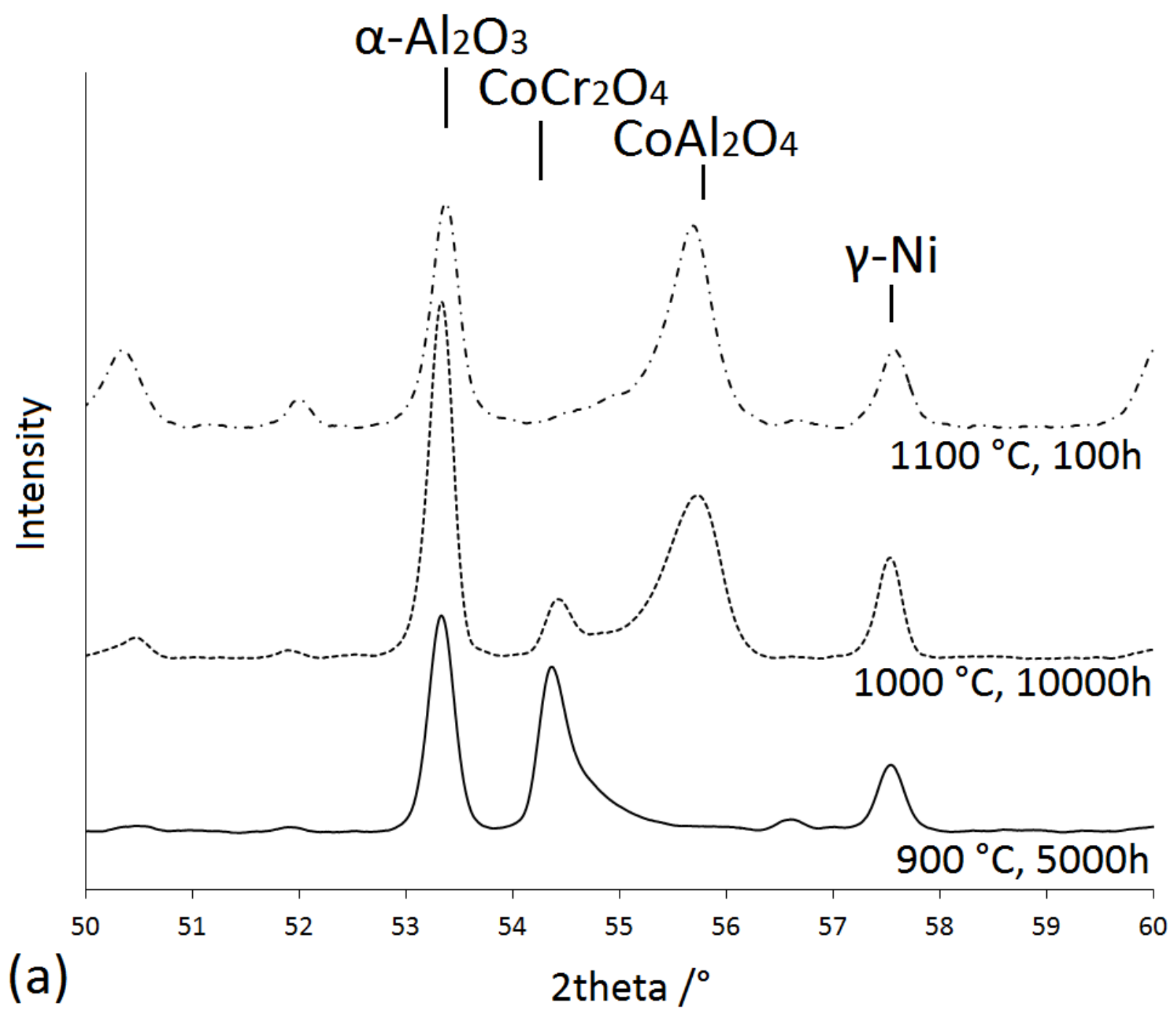




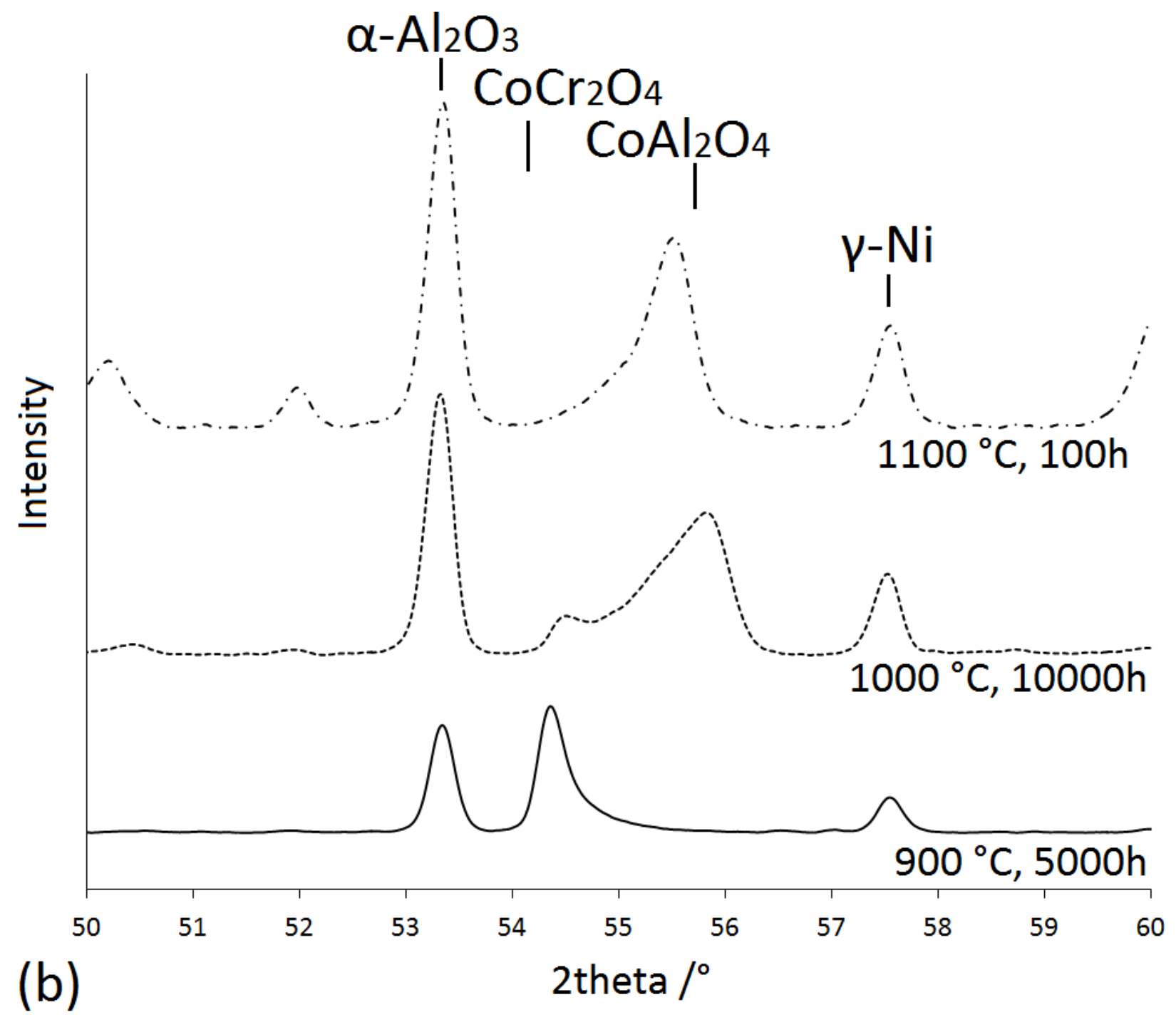

Figure 13. XRD spectra showing the spinels with a $\mathrm{CoCr}_{2} \mathrm{O}_{4}$ structure at lower temperature but with a $\mathrm{CoAl}_{2} \mathrm{O}_{4}$ structure at higher temperature: (a) for coating $\mathrm{A} 0$, (b) for coating $\mathrm{B} 1$. 

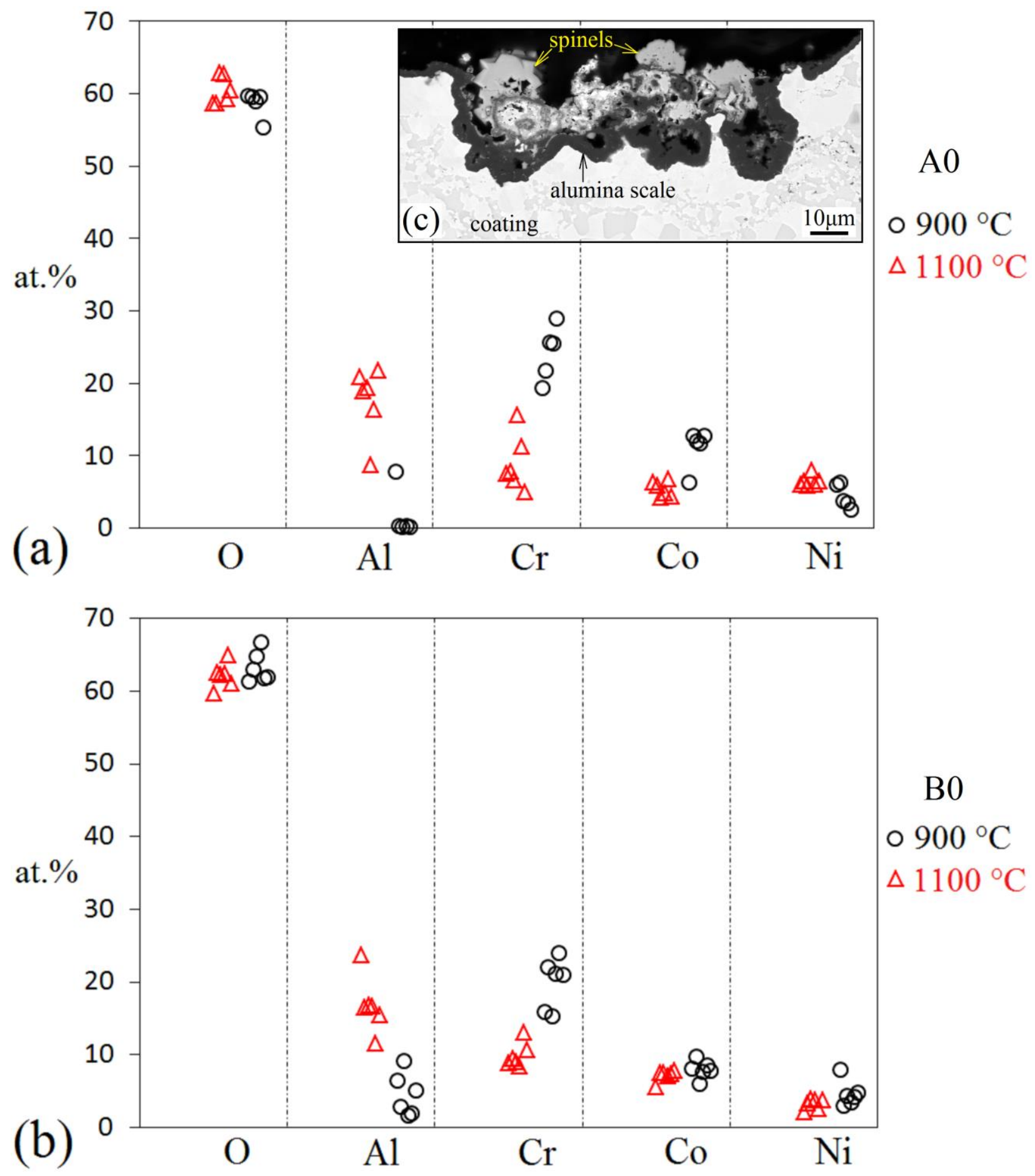

Figure 14. Compositions of spinels measured by quantitative EDS. The results for $900{ }^{\circ} \mathrm{C}$ are taken from the sample after oxidation process for $5000 \mathrm{~h}$, while the results for $1100{ }^{\circ} \mathrm{C}$ are for $100 \mathrm{~h}$. The EDS measurement is done on the cross section of samples. Figure (c) gives an example of a cross section of coating A0 after oxidation at $900{ }^{\circ} \mathrm{C}$ for $5000 \mathrm{~h}$, showing alumina scale and spinels. 


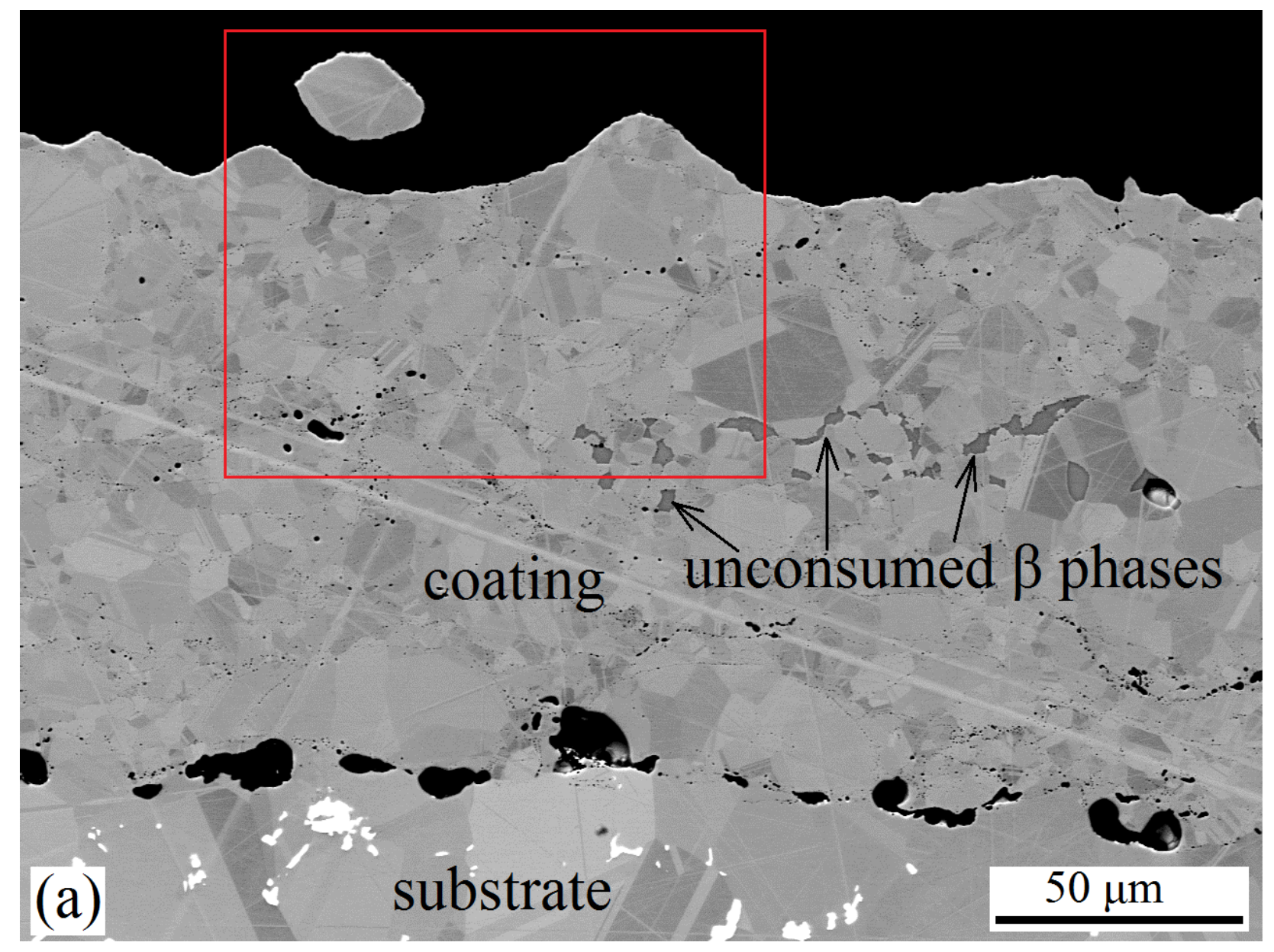



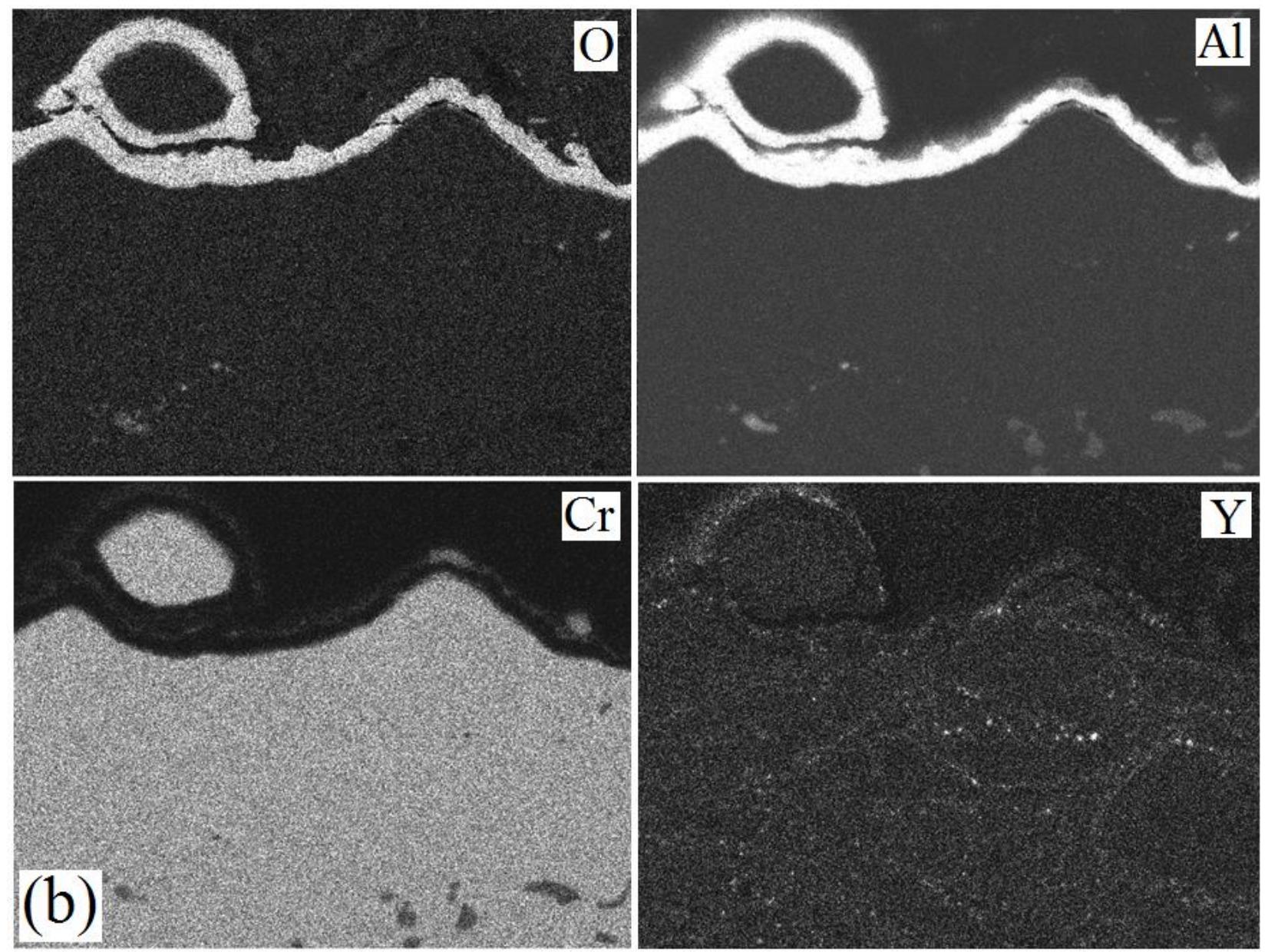

Figure 15. (a) BSE image showing the cross section of coating B0 after oxidation at $1100{ }^{\circ} \mathrm{C}$ for $500 \mathrm{~h}$, (b) EDS mapping of the area marked by red square in figure (a). 


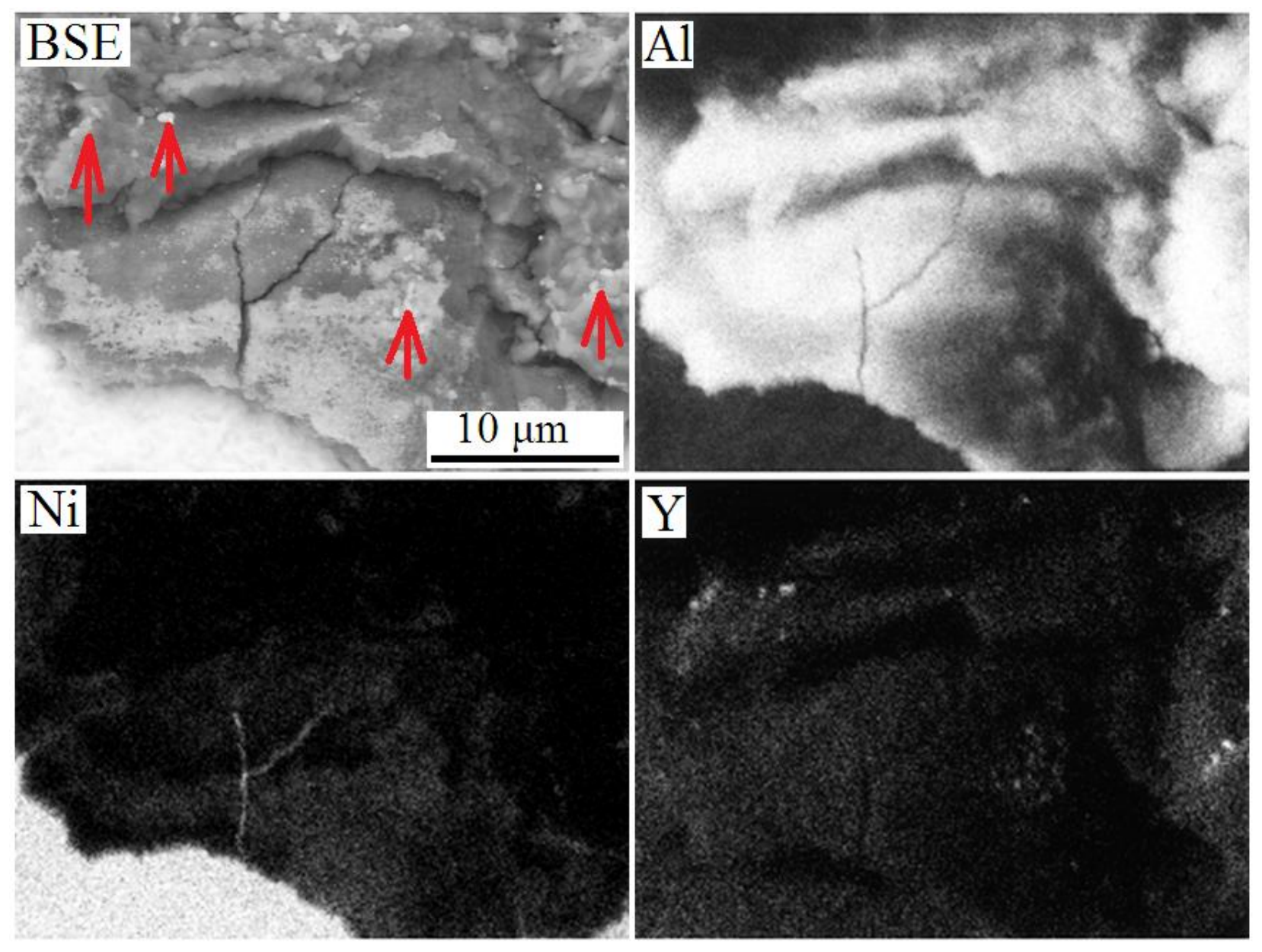

Figure 16. EDS mapping on the layer-by-layer alumina scales on the coating surface. The red arrows mark some Y-rich particles. 


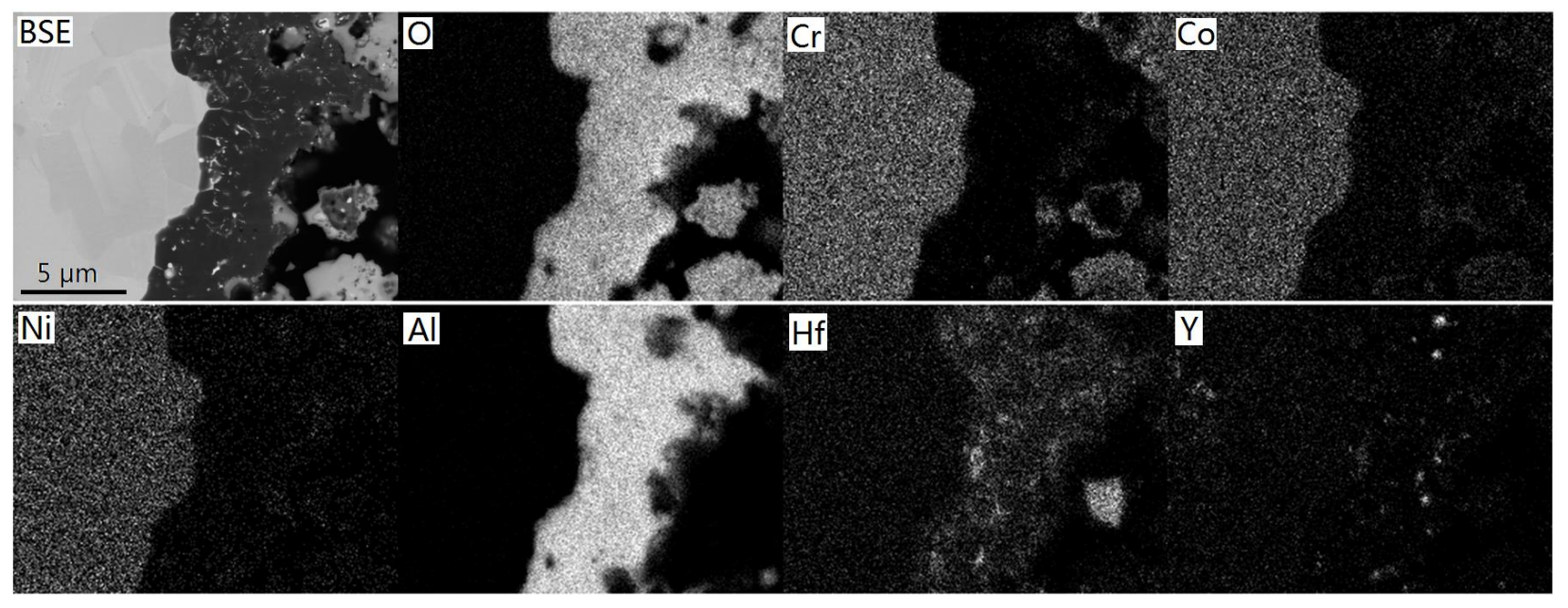

Figure 17. EDS mapping on Hf-containing oxide layer in the coating $\mathrm{B} 3$ after oxidation at $1000^{\circ} \mathrm{C}$ for 1000 hours. The coating surface is to the right. 

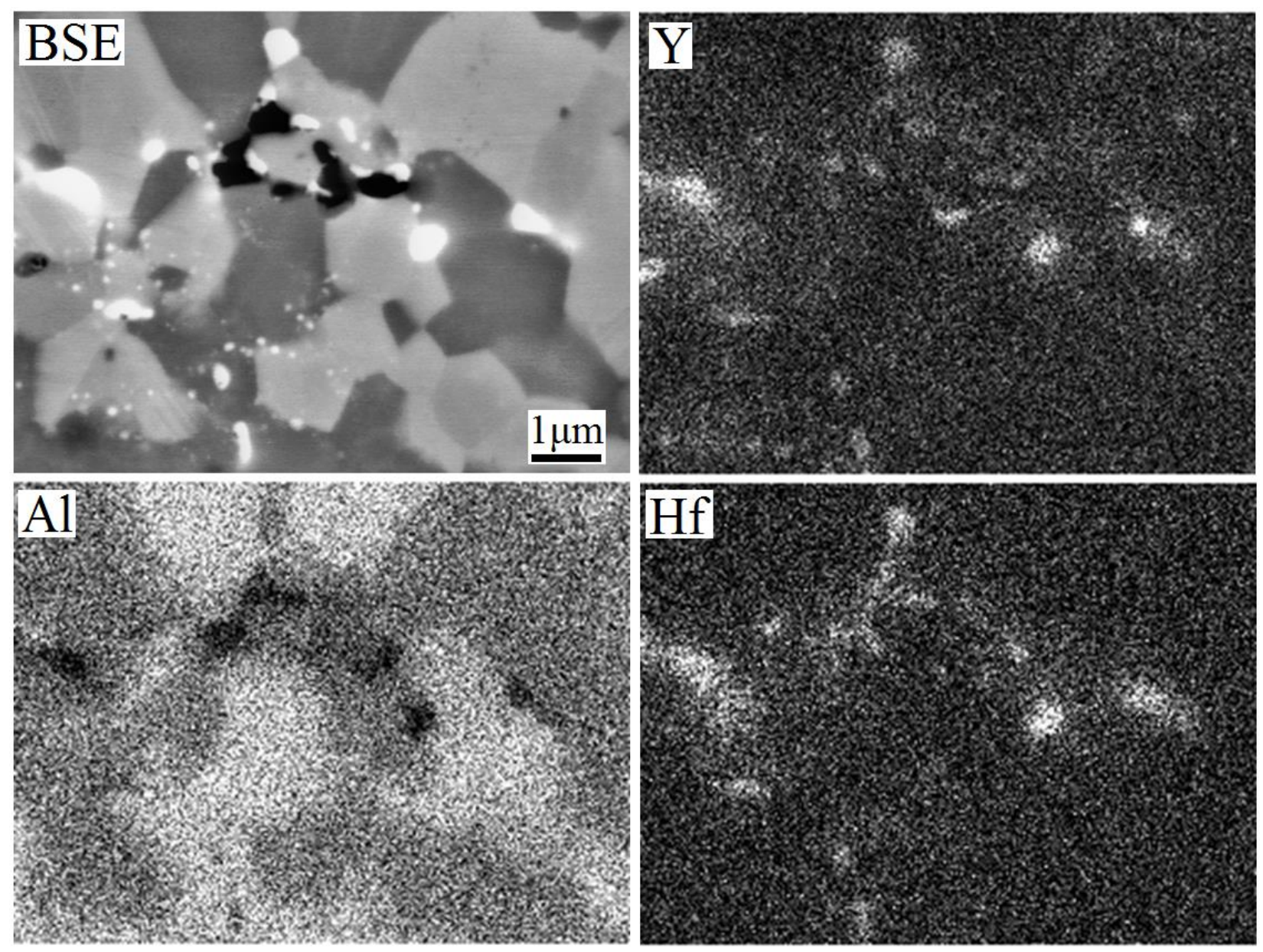

Figure 18. EDS mapping on a part of cross section of coating B3 after oxidation at $1000{ }^{\circ} \mathrm{C}$ for 1000 hours, showing the $\mathrm{Y}$ and $\mathrm{Hf}$ rich particles. 

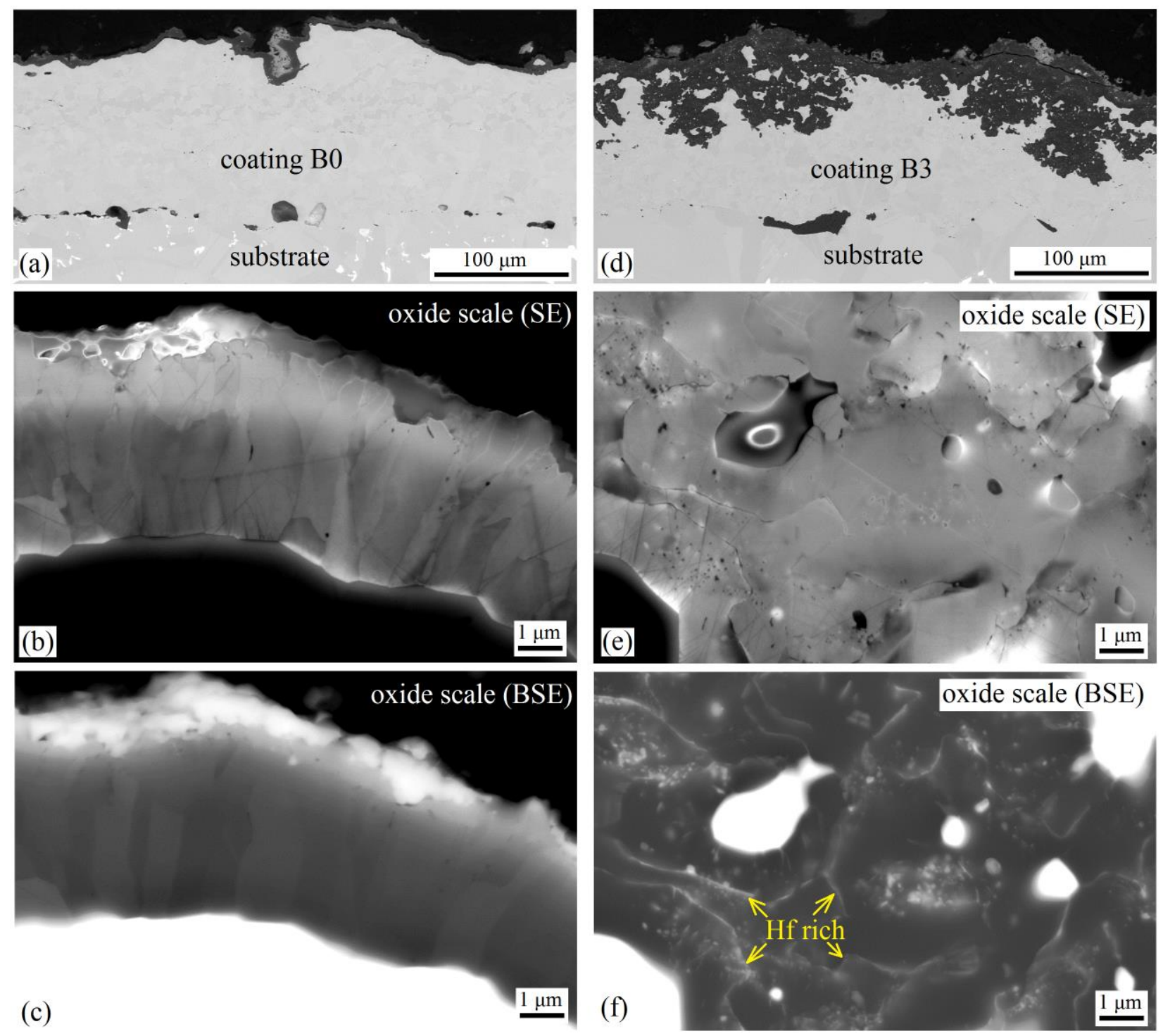

Figure 19. Comparison of the oxidation behavior between coating B0 and B3 at $1000{ }^{\circ} \mathrm{C}$ for $10000 \mathrm{~h}$. Figure (a), (b), (c) are for B0, and (d), (e), (f) for B3. (a) and (d) are showing the overview of the cross sections of the coatings (BSE). (b), (c), (e), (f) are showing the high-resolution morphology of the oxide scales in SE and BSE modes. The brighter phases above the alumina scale in (c) are spinels. 